\title{
Ideologías lingüísticas de las comunidades quechua y amazigh en Cataluña: el efecto espejo
}

\begin{abstract}
Albert Badosa Roldós
Este artículo estudia las ideologías lingüísticas de las comunidades de herencia quechua y amazigh residentes en Cataluña. Las ideologías lingüísticas se evalúan en relación con el concepto de "efecto espejo”, esto es, el impacto ideológico sobre los hablantes de lenguas de herencia minorizadas que se produce cuando entran en contacto con otra comunidad a su vez minorizada -en este caso Cataluña y la lengua catalana- $y$, en consecuencia, cambian sus representaciones, prácticas e ideologías lingüísticas. La investigación ha implicado la recopilación y análisis de datos cualitativos y cuantitativos, así como observación participante. Los datos cuantitativos fueron obtenidos mediante 82 cuestionarios y los cualitativos mediante 15 entrevistas semiestructuradas. El presente estudio es el primero que analiza el fenómeno del efecto espejo en comunidades concretas, que no se limita al estudio de individuos aislados. Además, es uno de los pocos estudios que analiza las ideologías lingüísticas de comunidades de herencia de origen minorizado.
\end{abstract}

Palabras claves: ideologías lingüísticas, efecto espejo, migración, lenguas de herencia, amazigh, quechua.

Language ideologies of the Quechua and Amazigh communities in Catalonia: the mirror effect. This paper studies the language ideologies of the Quechua and Amazigh heritage communities living in Catalonia. These language ideologies are studied in relation to the concept of "mirror effect", which makes the speakers of minoritised languages change their linguistic representations, practices and ideologies when contacting another minoritised community, in this case Catalonia and the Catalan language (CortèsColomé et al. 2016). The research includes the gathering and analysis of quantitative and qualitative data, together with participant observation. Quantitative data were obtained through 82 surveys, and qualitative data through 15 semi-structured interviews. This study is the first that analyses the mirror effect phenomenon on specific communities, and not only on individuals. It is also one of

Lengua y migración / Language and Migration 12:1 (2020) Monográfico, 127-173 Edición impresa: ISSN 1889-5425. Edición en línea: ISSN 2660-7166. @ Universidad de Alcalá 
the few studies analysing the language ideologies of heritage communities a minoritised origin.

Keywords: language ideologies, mirror effect, migration, heritage languages, Amazigh, Quechua.

\section{Introducción y objetivos de la investigación}

El estudio de las lenguas de la inmigración o lenguas de herencia es un fenómeno reciente y un campo de estudios en auge. Se denominan lenguas de herencia aquellas habladas por una comunidad inmigrante en un territorio determinado (Aalberse y Muysken 2013; Van Deusen-Scholl 2003, según King y Ennser-Kananen 2013).

Las lenguas de herencia se suelen considerar lenguas amenazadas o minorizadas por la tendencia a interrumpir su transmisión en los países de acogida (Blas-Arroyo 1995: 455; Edwards 2010: 21, según Larrea 2017: 51; Ogoshi y Hayasi 2004: vi). Estudiar los factores que pueden facilitar o dificultar el mantenimiento de las lenguas de herencia es de suma importancia hoy en día, en una época glocal (Boix 2015: 143-167) en la que se están buscando nuevos equilibrios ecolingüísticos que aboguen por el pluri- o multilingüismo y se desmarquen de la clásica concepción del estado-nación: un estado, una lengua (Bastardas 1996: 129). El estudio de las ideologías lingüísticas de los hablantes de lenguas de herencia es significativo por lo que atañe a las lenguas de herencia en sí y a su mantenimiento y, del mismo modo, para las lenguas del país de acogida.

En Cataluña hay una preocupación reciente por la relación entre la llamada "nueva inmigración" -venida de América, Asia y África a partir de los años ochenta- y las lenguas de Cataluña debido a la situación sociolingüística particular del territorio. Las encuestas de uso lingüístico demuestran un declive en el uso de las lenguas autóctonas de la comunidad autónoma de Cataluña, el catalán y el occitano (no hay datos para la lengua de signos catalana). El uso del catalán ha caído de un $46 \%$ a un $36,6 \%$ entre 2003 y 2013. Asimismo, el catalán como lengua inicial ha descendido de un $36,2 \%$ a un $31 \%$ en el mismo periodo. El castellano ha permanecido como la lengua más usada en 2003 y 2013, con un porcentaje de alrededor del $55 \%$ en ambos años. Como lengua inicial, ha subido del 42,2\% de 2003 al 50,7\% de 2013 (véase Estadística d'Usos Lingüístics a Catalunya 2003, 2005; Enquesta d’Usos Lingüístics de la Població 2013, 2015).

Lengua y migración / Language and Migration 12:1 (2020) Monográfico, 127-173

Edición impresa: ISSN 1889-5425. Edición en línea: ISSN 2660-7166. @ Universidad de Alcalá 
La "nueva inmigración" representa hasta un $15 \%$ de la población de Cataluña. Esto hace que un 10,6\% de catalanes no tenga ni el catalán, ni el occitano ni el castellano como lengua inicial (EULP 2013, 2015: 30). Los aloglotos en Cataluña se han incrementado en 400,000 entre 2003 y 2013 (Direcció General de Política Lingüística 2015: 16). La gran mayoría de este $10 \%$ de catalanes se incorpora a la sociedad a través del castellano (DGPL 2015: 27; 59). Estos datos reflejan la alteración de la dinámica sociolingüística en Cataluña explicada en el párrafo anterior.

Ante este desafío para las lenguas autóctonas de Cataluña, han surgido propuestas para revertir la caída de su uso. El Grup d'Estudi de Llengües Amenaçades (en adelante GELA) de la Universidad de Barcelona apuesta por el multilingüismo social, contrapuesto al bilingüismo social, con el objetivo de:

(1) integrar las lenguas de herencia en la sociedad catalana de una forma respetuosa y enriquecedora para todos los catalanes y

(2) reforzar el catalán como lengua preferente en un contexto multilingüe (Barrieras 2013).

El GELA ha estado trabajando muchos años con las lenguas de herencia en Cataluña. Uno de sus trabajos más ingentes ha sido inventariar las lenguas de herencia de los catalanes, que ya superan las 300 lenguas. ${ }^{1}$ Durante este trabajo de campo, que consistió en entrevistar individuos que habían cambiado de hábitos lingüísticos en relación con sus lenguas de herencia -detectados cuando se inventariaban las lenguas de herencia habladas en Cataluña- los miembros del GELA descubrieron el fenómeno al que llamaron "efecto espejo" (Barrieras y Monrós 2005; Cortès-Colomé et al. 2016; Junyent et al. 2011).

Así, el presente artículo pretende ampliar los escasos estudios sobre el efecto espejo con los siguientes objetivos:

(1) Analizar las ideologías lingüísticas de las comunidades quechua y amazigh en Cataluña en relación al efecto espejo en términos de presencia o ausencia del efecto espejo (individuos afectados y no afectados).

(2) Comparar las ideologías lingüísticas de los grupos minoritarios (quechua y amazigh) con las ideologías lingüísticas de los grupos dominantes correspondientes (marroquíes y latinoamericanos).

(3) Proporcionar una escala descriptiva con 3 fases procesuales y progresivas de experimentación del efecto espejo en las personas.

Lengua y migración / Language and Migration 12:1 (2020) Monográfico, 127-173 Edición impresa: ISSN 1889-5425. Edición en línea: ISSN 2660-7166. @ Universidad de Alcalá 
(4) Establecer qué factores facilitan o dificultan el proceso del efecto espejo y/o determinan las ideologías lingüísticas de cada comunidad.

\section{Marco teórico}

En esta sección se definirá el concepto de efecto espejo, se describirán las características de las comunidades quechua y amazigh en Cataluña y se revisarán los trabajos hechos sobre las ideologías lingüísticas en Cataluña, describiendo los conceptos clave que se usarán en el artículo, así como los trabajos hechos sobre las ideologías lingüísticas de los latinoamericanos y los marroquíes.

\subsection{El efecto espejo}

El efecto espejo es el fenómeno sociolingüístico y sociocultural desencadenado cuando los miembros de una comunidad entran en contacto con la situación social, cultural, lingüística y política de una comunidad minorizada. Este contacto actúa como estímulo, provocando que los miembros de la comunidad desplazada reevalúen su herencia cultural y lingüística así como reinterpreten y reconfiguren sus orígenes y representaciones lingüísticas. (Cortès-Colomé et al. 2016: 276-281).

En el caso de Cataluña, los investigadores del GELA han descubierto que algunos migrantes reevalúan la interpretación de la situación sociolingüística de sus lenguas de herencia, además, cambian su comportamiento lingüístico: los usos lingüísticos respecto al catalán y/o sus lenguas de herencia, las representaciones lingüísticas y las ideologías lingüísticas. Algunos, pues, se tornan activistas por la lengua y adoptan el catalán como lengua preferente: "como más catalán hablo, más tártara estoy (sic)” (Junyent et al. 2011: 98-99).

En consecuencia, el efecto espejo proyecta la representación formada en Cataluña hacia sus sociedades de origen, creando una suerte de solidaridad entre comunidades minorizadas y fomentando ideologías lingüísticas favorables al multilingüismo y a la diversidad lingüística y cultural (Cortès-Colomé et al. 2016: 275-281).

Cataluña es un territorio propenso a actuar como estímulo cultural y lingüístico por su situación sociolingüística característica: aunque el catalán es una lengua minorizada, ocupa roles reservados normalmente a lenguas dominantes (Cortès-Colomé et al. 2016: 276-281; DGPL

Lengua y migración / Language and Migration 12:1 (2020) Monográfico, 127-173

Edición impresa: ISSN 1889-5425. Edición en línea: ISSN 2660-7166. @ Universidad de Alcalá 
2015: 51). En otras palabras, es muy improbable no entrar en contacto con el catalán en el día a día en el Principado.

Así pues, se han escogido para esta investigación dos de las mayores comunidades en Cataluña y que además provienen de un origen minorizado o, dicho de otro modo, cuyas lenguas de herencia están minorizadas y discriminadas: la quechua y la amazigh, (véase Coronel-Molina 2007; King y Hornberger 2004 para el quechua, y Boukous 2011; Bullock 2014; El Aissati 2001 para el amazigh).

\subsection{Las comunidades amazigh y quechua en Cataluña}

Entre la comunidad amazigh hay muchos endónimos y exónimos (Barrieras 2013: 13). A pesar de la gran cantidad de denominaciones para la lengua y la identidad nacional, todos los participantes aceptan la denominación común "amazigh", seguramente relacionado con el auge del movimiento amazigh (Maddy-Weitzman 2012). Para esta investigación se emplea el término "amazigh" y se evita usar el término "bereber", de connotaciones despectivas.

Si ya resulta difícil contabilizar los hablantes de lenguas minorizadas en sus territorios autóctonos, aún lo es más en sus territorios de acogida. Hay dos dificultades principales a la hora de contabilizar hablantes de lenguas minorizadas: primero, su invisibilización por parte de la administración pública que actúa en el marco de estadonación; en segundo lugar la ocultación de estas lenguas por los propios hablantes. Esta problemática ha sido observada por Comellas et al. (2010). Así, la vergüenza y ocultación de la propia lengua son fenómenos característicos de los hablantes de quechua, dificultando enormemente su censo (King y Hornberger 2004). En detalle, el quechua es hablado en Perú, Bolivia, Ecuador, Chile, Colombia y Argentina por unos 10 millones de personas, de los cuales 4.000 .000 se encuentran en Perú, alrededor de 2.000 .000 en Ecuador y otros 2.000 .000 aproximadamente en Bolivia (Gràcia 2010: 1-2).

La nacionalidad ecuatoriana es la tercera nacionalidad más común entre la inmigración de Cataluña, con unos 50.000 individuos. La nacionalidad peruana y boliviana comprenden aproximadamente 20.000 personas respectivamente, sumando en total unas 90.000 personas que provienen de estos países donde más se habla quechua -Perú, Bolivia y Ecuador (Barrieras 2013: 2). Otra dificultad a la hora de contabilizar a los migrantes, sin embargo, es que los latino-americanos residentes en España pueden obtener la nacionalidad española después de 2 años de residencia, por lo que estas cifras podrían ser mucho mayores (Alarcón 
y Garzón 2011: 45). Podemos suponer que en Cataluña hay varios miles de hablantes de quechua.

Por otro lado, ha habido intentos más exhaustivos de contabilizar los hablantes de amazigh, mucho más numerosos en Cataluña. El amazigh es una lengua afroasiática hablada en el Norte de África por más de 30 millones de personas. Es hablada por un $40 \%$ de la población de Marruecos y el 25\% de la población de Argelia (Fidalgo 2015: 95; Lamuela 2005: 1-2).

La nacionalidad marroquí es la más representada en Cataluña, con más de 240.000 personas, cifra que representa más del $20 \%$ de la inmigración total. En un principio, se asumió que todos los marroquíes hablaban árabe, no obstante, la mayoría de marroquíes de Cataluña hablan amazigh, concretamente entre un $50 \%$ y un $80 \%$. Así pues, muchos autores asumen que el amazigh es la tercera lengua más hablada de Cataluña, solo por detrás del castellano y el catalán (Barrieras 2013: 9-10). Este dato es poco conocido y los amagizohablantes tienen problemas de visibilización, especialmente en lo que atañe a la administración pública.

\subsection{Ideologías lingüísticas en Cataluña}

Kathryn Woolard es una reconocida investigadora que ha acuñado dos conceptos clave: autenticidad y anonimidad. Por un lado, la autora define autenticidad como "authenticity credits a language variety with value insofar as it expresses the essential, distinctive nature of a community or a speaker, a view associated with Romantic particularism". Tiene que ver con el valor sentimental y esencial de la lengua para una comunidad, y puede estar relacionado con su folklorización. Muchas lenguas minorizadas son, por tanto, auténticas. Por otro lado, una lengua es anónima cuando "is valuable as a neutral, objective vehicle of expresión equally available to all users, a view associated with enlightenment universalism". Es decir, una lengua es anónima cuando es la lengua de facto de un determinado territorio o comunidad (Woolard 2008: 304-306).

La autora considera que en Cataluña el catalán es una lengua auténtica y el castellano una lengua anónima, aunque la misma autora recientemente ha documentado "a trend to displace the source of authority for Catalan away from authenticity and toward anonymity, and even beyond to a new, still inchoate legitimating ideology that challenges both of these modern discourses." (Woolard y Frekko 2013: 134-135). Como veremos, estos conceptos son aplicables tam- 
bién a las lenguas de herencia. A continuación, se detallará qué papel juegan en las ideologías lingüísticas de ambas comunidades.

En línea con lo anterior, Larrea propone el concepto de transposición (2017: 137). Según Larrea, la transposición es el fenómeno por el cual un individuo interpreta la situación sociolingüística de un territorio determinado a través de la matriz sociolingüística de su territorio de origen, buscando paralelismos.

\subsection{Ideologías lingüísticas de los grupos dominantes: marroquíes y latinoamericanos}

Desafortunadamente, no hay otros estudios sobre las ideologías lingüísticas de quechuas y amazigh en Cataluña. Los estudios sociolingüísticos tienden a coger como marco el estado-nación y sus lenguas nacionales, invisibilizando las lenguas no estatales. Es interesante, sin embargo, comparar las ideologías lingüísticas de los quechuas con las de los latinoamericanos, y las de los amazigh con los marroquíes. Así podremos observar posibles diferencias, así como ver comparativamente la incidencia del efecto espejo.

Los estudios sobre ideologías lingǘsticas de los latinoamericanos no suelen diferenciar nacionalidades. Las ideologías lingüísticas más comunes y consensuadas descritas en los estudios consultados (Comellas 2006; Corona 2016; Alarcón y Garzón 2011; Garzón 2012; Newman 2011; Patiño-Santos 2018; Sanvicén-Torné 2017) son:

- El hecho de que el castellano sea la lengua dominante tanto en Latinoamérica como en España es determinante para sus ideologías lingüísticas.

- Las ideologías monolingüistas y de estado-nación son bastante comunes, incluso en individuos plurilingües.

- Racialización, minorización y estigmatización extremas en relación con el componente indígena.

- Jerarquía lingüística rígida, que sitúa el inglés por delante del castellano como lengua más importante y las otras lenguas son consideradas patois.

- Cierta hostilidad y actitudes negativas hacia el catalán.

Los estudios sobre las ideologías lingüísticas de la inmigración marroquí consultados (Alarcón y Garzón 2011; Comellas 2006; Sanvicén-Torné 2016, 2017; Vila et al. 2013) convienen en que son:

- Neutralidad o cierta animosidad hacia el catalán. 
- Valoración del catalán y castellano similares. Se considera que el esfuerzo de conocer las dos es bajo y parecido.

- Ideologías multilingüistas: cuantas más lenguas se sepan, mejor.

- Diferencias en ideologías lingüísticas según el género.

En un estudio comparativo, Alarcón y Garzón (2011) identifican algunas ideologías lingüísticas compartidas entre las comunidades latinoamericana y marroquí:

- Fuerte relación entre identidad y patrimonio tradicional, pero de bajo prestigio y visto como poco útil.

- Percepción del catalán como capital cultural fuerte que sirve de ascensor social.

- Percepción del castellano como útil, como lengua anónima y lengua principal de comunicación.

\section{Metodología}

Para este trabajo se han usado técnicas cuantitativas y cualitativas. El análisis de datos se llevó a cabo combinando ambas técnicas. Los datos cuantitativos fueron obtenidos a través de encuestas, con versiones en catalán y castellano para ambas comunidades.

Primeramente, las encuestas incluyen 8 preguntas iniciales sobre el perfil del participante: edad, lugar de nacimiento, lugar de nacimiento de los padres, educación, profesión, lengua materna y qué lenguas conocen y con qué nivel. En la segunda parte de la encuesta se proporcionarn 7 preguntas del tipo escala de Likert, en las que las diferentes lenguas de cada comunidad se valoraron en una escala de 1 a 5 en relación a diferentes áreas -escuela, trabajo, cultura tradicional, cultura del alrededor, identidad, el futuro de los hijos y bienestar.

Por un lado, las lenguas por las que se preguntó a la comunidad quechua son: catalán, castellano, quechua e inglés. Por otro, las de la comunidad amazigh son: catalán, castellano, amazigh, árabe e inglés. Finalmente, la encuesta termina con una pregunta final también de escala de Likert, encarada al efecto espejo, que pregunta si la situación sociolingüística de la comunidad de origen se parece a la catalana.

El protocolo empírico estaba, además, formado entrevistas semiestructuradas. También se llevaron a cabo sesiones de observación participante durante actividades sociales, culturales y educativas de ambas comunidades. Todas las entrevistas siguieron un guion preestablecido, que preveía cubrir las cuestiones siguientes: trayectoria vital y migra-

Lengua y migración / Language and Migration 12:1 (2020) Monográfico, 127-173

Edición impresa: ISSN 1889-5425. Edición en línea: ISSN 2660-7166. @ Universidad de Alcalá 
toria, primeras etapas de la vida, esfera familiar, esfera laboral, esfera académica y relación con las lenguas diacrónica y sincrónicamente. Todos estos temas se trataron en relación con las lenguas. Además, también se administró el cuestionario a los entrevistados y se comentaron las respuestas de las preguntas de Likert sobre ideologías lingüísticas.

Los datos recopilados incluyen 34 cuestionarios rellenados por la comunidad quechua y 48 rellenados por la comunidad amazigh, así como 6 entrevistas semiestructuradas llevadas a cabo con participantes quechua y 9 entrevistas llevadas a cabo con participantes amazigh. Todos los participantes entrevistados también respondieron al cuestionario, pero la muestra de encuestados tiene sesgos diferentes a la muestra de entrevistados. En el caso amazigh sobretodo, hay una sobrerrepresentación de menores de 25 años y de mujeres, lo que no coincide con el perfil mayoritario de los entrevistados; hombres mayores de 35 años.

Todos los 9 participantes amazigh son de origen marroquí. Los 6 participantes quechua son de origen peruano, ecuatoriano y boliviano. La Tabla 1 muestra la nomenclatura empleada para presentar las transcripciones de las entrevistas semiestructuradas. La Tabla 22 (Anexo) lista todos los participantes de las entrevistas según la nomenclatura correspondiente a la Tabla 1.

\begin{tabular}{|l|l|}
\hline Q/A & Participante quechua / participante amazigh \\
\hline I, $2,3 \ldots$ & Número de la entrevista en orden temporal. \\
\hline H / D & Género del participante: $\mathrm{H}$ - hombre / D - mujer \\
\hline $30,35,40 \ldots$ & Edad aproximada del participante. \\
\hline
\end{tabular}

Tabla 1. Convención de nomenclatura para las entrevistas semiestructuradas.

\subsection{Cuestiones sobre el trabajo de campo}

Los cuestionarios fueron distribuidos on-line en un primer momento. Hubo una buena respuesta por parte de la comunidad amazigh pero no hubo ninguna respuesta por parte de la comunidad quechua. Así, la gran mayoría de encuestas rellenadas por la comunidad quechua fueron administradas en persona. En lo que atañe a la comunidad amazigh, un $40 \%$ de encuestas fueron administradas en persona y un $60 \%$ on-line. La naturaleza de la obtención de los datos cuantitativos, por tanto, es más de carácter etnográfico que de carácter aleatorio.

Los contactos con las comunidades se establecieron de distintos modos: (1) la red social propia del investigador, (2) profesores y estu- 
diantes de la Universidad de Barcelona, (3) periodistas e investigadores trabajando con esas comunidades, (4) la escuela pública catalana, (5) diversas organizaciones culturales de cada comunidad y (6) restaurantes.

Esta variedad contribuyó a que los perfiles socioeconómicos, culturales y geográficos fueran diferentes. Cabe destacar, sin embargo, un sesgo detectado durante el trabajo de campo: la sobrerrepresentación de participantes amazigh de cierto perfil -activistas políticos y culturales conscientes de su identidad amazigh-, especialmente en los datos cualitativos.

El análisis de datos de este artículo resulta de una combinación de los datos cualitativos y los cuantitativos. Los cuestionarios se proporcionaron y procesaron por medio de Google Forms. Las entrevistas se grabaron usando un teléfono Samsung exceptuando dos de ellas, que no pudieron ser grabadas y fueron transcritas después de la entrevista, con el consentimiento de los participantes. Todos los datos han sido anonimizados y los participantes dado su consentimiento a participar en la investigación.

\subsection{El rol del investigador}

Uno de los factores de mayor importancia durante el trabajo de campo fue la cuestión del rol del investigador. Esta cuestión la han tratado sociolingüistas como Labov (1972), Meyerhoff et al. (2012) o Sallabank (2013) así como Heller, Pujolar y Pietikäinen (2017) que incluyen una sección sobre trabajo de campo sociolingüístico en Cataluña.

Por un lado, Labov (1972) se refiere a los problemas derivados del rol del investigador como 'la paradoja del observador', por otro, Sallabank los define 'la paradoja del investigador', por la cual la presencia del investigador influye en los datos observados o recopilados por el mismo (2013: 60). La mayor influencia en el caso que nos ocupa fue en las actitudes lingüísticas en general y especialmente hacia el investigador.

Antes de cada sesión de trabajo de campo el investigador (1) clarificó su posición, (2) explicó los objetivos básicos del estudio, y (3) trabajó para ganarse la confianza de los participantes, siguiendo a Meyerhoff et al. (2012: 124-125). A parte de razones de honestidad, este procedimiento minimiza el impacto del investigador.

Heller, Pujolar y Pietikäinen afirman que la identidad y el rol social del investigador ya ha afectado el inicio de la investigación al escoger el tema (2017: 30-31; 67-65). Así, en lugar de tratar de minimizar el efecto del rol del investigador se tiene que aceptar como parte de la investiga-

Lengua y migración / Language and Migration 12:1 (2020) Monográfico, 127-173

Edición impresa: ISSN 1889-5425. Edición en línea: ISSN 2660-7166. @ Universidad de Alcalá 
ción, incluso como tema de investigación en sí mismo. Es por este motivo que se incluyó la clarificación previa que he referido para tomar consciencia del sesgo que supone la paradoja del investigador y tenerla en cuenta durante el análisis de datos y la discusión. Los autores, además, consideran el proyecto de investigación como una intervención política que afecta tanto los participantes como la sociedad (ibid.). El caso es que todo lo que tiene que ver con lengua en Cataluña también tiene que ver con política, y esta constatación estuvo presente constantemente en los análisis del investigador.

Así, uno de los objetivos del investigador ha sido y es el de influir en la sociedad catalana y las comunidades investigadas desde un punto de vista de defensa de las lenguas de herencia y las lenguas amenazadas, así como de la diversidad lingüística en general. La posición del investigador es la de un estudiante joven de máster en una universidad inglesa, hablante nativo de catalán, no racializado e interesado en la revitalización de lenguas y la diversidad lingüística.

Tanto Meyerhoff et al. (2012) como Heller, Pujolar y Pietikäinen (2017) señalan las restricciones culturales y tabús sociales durante el trabajo de campo según la relación del investigador con la comunidad: como agente interno o externo, como es el caso. Durante el trabajo de campo, se prestó especial atención a problemáticas de género, clase social y alfabetización en catalán y castellano, sobre todo con la comunidad amazigh. En lo que atañe a la comunidad quechua, se prestó atención a en qué circunstancias es posible hacer investigación y en qué no, así como a cuestiones de racialización.

La decisión más complicada durante el trabajo de campo, que se tenía que tomar constantemente, fue qué lengua hablar en cada momento. Como ya se ha visto en la introducción, en Cataluña hay dos lenguas que compiten en el mismo territorio y la dominante, el castellano, se está imponiendo a la minorizada, el catalán.

Al comienzo del trabajo de campo, tanto durante las visitas como durante entrevistas, siempre se habló en catalán a los participantes y se cambió al castellano si alguno lo pedía. Esta estrategia se pudo mantener sin problemas con la comunidad amazigh, no obstante, con la comunidad quechua se descubrió que para ser realmente neutral se tenía que empezar en castellano y en todo caso preguntar si sabían y entendían el catalán. Hubo diferencias manifiestas entre las dos comunidades: por un lado, entre los amazigh el investigador pudo animar a algunos a lanzarse a hablar en catalán, a pesar de decir que no lo hablaban o lo hablaban mal. Por el otro, en algunas ocasiones fue reprobado por hablar catalán por participantes quechuas. Así, el catalán provocó actitudes positivas, generalmente, o neutrales en la comunidad amazigh y negativas o neutrales entre los quechuas.

Lengua y migración / Language and Migration 12:1 (2020) Monográfico, 127-173 Edición impresa: ISSN 1889-5425. Edición en línea: ISSN 2660-7166. @ Universidad de Alcalá 
Además, la clarificación ideológica de la postura del investigador provocaba que algunos participantes modificaran su discurso para satisfacer las expectaciones que se esperaban del investigador -una persona externa a la comunidad, no racializada, hablante nativo de catalán y con una posición socioeconómica generalmente más elevada-. Este fenómeno es llamado "question threat" por Foddy (1993: 120123), en lo relativo a cuestionarios. Especialmente los quechuas, pero también los amazigh, cambiaban el discurso para alabar el catalán o la diversidad lingüística, o prometiendo que aprenderían más catalán, pero después describían prácticas lingüísticas totalmente diferentes. En el caso amazigh, este fenómeno se constató especialmente con la diferencia entre las respuestas de las encuestas contestadas presencialmente y las respuestas contestadas online. Además, se detectó una influencia altamente significativa del complejo racial $^{2}$ de herencia colonial en los quechuas, que hacía que se alterizara al investigador.

Esta cuestión está problematizada también por Heller, Pujolar y Pietikäinen (2017) como "percepción e impresión del investigador". Pujolar, que cuenta su experiencia en Cataluña, describe un ejemplo interesante de cómo fue tratado como investigador y las respuestas que obtuvo en comparación a la experiencia de Kathryn Woolard en Cataluña como miembro externo a la comunidad (ibid. 58-59).

\subsection{Cuestiones sobre las encuestas}

Finalmente, es relevante para la interpretación de los datos discutir la problemática derivada del trabajo de campo cuantitativo. En este sentido, Low (1999) refiere problemas derivados de las preguntas de escala de Likert: restricciones de interpretación relacionadas con malentendidos, malinterpretación de las intenciones del investigador o el orden de las preguntas o su formulación. Todos estos fueron identificados en los datos del estudio, especialmente con la última pregunta, que tiene que ver con el efecto espejo.

Así, cuando se proporcionó la pregunta "¡cree que la situación del catalán y la situación del quechua/amazigh son parecidas?”, muchos quechuas interpretaron que se refería a cuestiones lingüísticas: "sí, son lenguas similares, hay expresiones similares que no existen en castellano, por ejemplo...". La comunidad amazigh en general parecía entender mejor la pregunta y estar de acuerdo con la frase, pero algunos respondían que no porque "son parecidas, pero hay diferencias". Así, delante de la misma interpretación de la pregunta, se obtenían respuestas muy diferentes.

Lengua y migración / Language and Migration 12:1 (2020) Monográfico, 127-173

Edición impresa: ISSN 1889-5425. Edición en línea: ISSN 2660-7166. @ U Universidad de Alcalá 
Esta pregunta sobre el efecto espejo ha sido consiguientemente retirada del análisis de datos por su inconsistencia y malinterpretación, que lleva a una no significancia de los datos. Así, el fenómeno del efecto espejo será analizado desde un punto de vista cualitativo, ya sea durante las entrevistas o a través de las conversaciones y percepciones durante el trabajo de campo cuantitativo o la observación participante.

\section{Análisis de datos}

Primero se tratarán los datos cualitativos del efecto espejo, que ayudarán a definirlo, y en segundo lugar se expondrán los datos cuantitativos para describir las ideologías lingüísticas. Algunas cuestiones relevantes referentes al análisis cuantitativo se ampliarán y complementarán con fragmentos de las entrevistas cualitativas.

\subsection{Análisis de los datos cualitativos. El efecto espejo}

Como hemos explicado, el efecto espejo es el fenómeno por el cual los miembros de un pueblo minorizado cambian sus representaciones lingüísticas al entrar en contacto con otro grupo minorizado. Se detectaron casos de efecto espejo tanto en el trabajo de campo cuantitativo como el cualitativo, pero nos centraremos en los datos cualitativos por la inconsistencia de los datos cuantitativos, que los invalidan.

\subsubsection{Efecto espejo en los participantes quechuas}

Así, 2 participantes quechuas de los 6 entrevistados muestran solidaridad con el caso de la lengua catalana y ven paralelismos con la situación del quechua. Esto ha llevado a la participante Q5D40 a redescubrir, revalorizar y reivindicar su identidad quechua, que antes negaba:

Q5D40: Pero ahora estoy recuperando mi lengua. Desde que he emigrado a Cataluña que me lo cuestionaba continuamente. Estaba aprendiendo una lengua que todo el mundo defendía muy bien, porque era su identidad y su lengua. Y me preguntaba por qué no he hecho yo nada por mi lengua y mi identidad.

Investigador: ¿Te refieres al catalán?

Lengua y migración / Language and Migration 12:1 (2020) Monográfico, 127-173 Edición impresa: ISSN 1889-5425. Edición en línea: ISSN 2660-7166. @ U Universidad de Alcalá 
Q5D40: Sí. El catalán es lo que ha despertado la necesidad de volver a aprender mi lengua y mis costumbres. [traducción propia del catalán]

El participante Q6H50, por otro lado, se ha convertido en un activista por la lengua y cultura quechuas en Cataluña, y defiende posturas plurilingüistas.

Investigador: ¿Crees que la situación del quechua y del catalán son semejantes? [TPC]

Q6H50: Sí, sí, sí. Tiene muchos puntos en común. Por ejemplo, ha habido momentos en la historia de España en que el catalán ha sido silenciado. Igual que en Perú, ha habido momentos en la historia en que ha sido arrinconado, hasta prohibido. En otros hechos también, es parecida la situación.

Q6H50: [Los quechuas] se sienten identificados, y entonces hacen una comparación y dicen... "nos corresponde rescatar mi lengua", y se identifican [con la situación catalana].

Investigador: ¿La mejora del quechua se parece a la mejora del catalán? [TPC]

Q6H50: Sí, sí, sí. En el curso de catalán de B1 que hice, y de los 18 que éramos había dos españolas que hacía 50 años que vivían en Catalunya y los otros éramos extranjeros de todos los países del mundo. [...] El catalán tendría que ser la primera lengua.

\subsubsection{Efecto espejo en los participantes amazigh}

En el caso de los participantes amazigh, el efecto espejo se ha encontrado en 8 de los 9 participantes entrevistados, aunque cabe destacar que la mayoría de los participantes provienen de asociaciones amazigh. Entre los participantes afectados por el efecto espejo, hay 3 casos diferentes:

(1) aquellos que ya tenían consciencia e identidad amazigh antes de emigrar a Cataluña (participantes A2H40, A6H40, A8D40 y A9H40) -generalmente adultos con estudios universitarios-,

(2) aquellos que descubrieron su identidad o la situación sociolingüística de minorización de su lengua y cultura una vez llegados a Cataluña (A1H45, A3D20, A4H20) -un adulto sin estudios universitarios y dos jóvenes llegados a Cataluña cuando eran muy pequeños-, y

(3) el caso de la participante A7D40, que pertenece a la clase media urbana arabizada que ha dejado de transmitir el amazigh:

Investigador: ¿Hay gente que te haya criticado por reivindicar tu identidad 
A7D40: He empezado a hacerlo hace poco tiempo. Cuando me preguntan digo "mis orígenes son bereberes, pero soy de Marruecos". Hace poco tiempo. En mi familia me toman como una loca. Sí, sí. Yo me considero bereber.

Los participantes del segundo grupo -concienciados una vez llegados a Cataluña- han empezado a encontrar paralelismos entre la situación catalana y la amazigh, y han empezado a participar en asociaciones culturales en Cataluña y a reivindicar su identidad, lengua y cultura propias. El participante A1H45, por ejemplo, se identifica con la clase trabajadora. Entró en contacto con el catalán por primera vez en una asociación de Cornellà, donde cambió sus ideologías y representaciones lingüísticas sobre el amazigh y el catalán. Es un activista comprometido con muchas causas, entre ellas el problema migratorio.

A1H45: Uso el catalán en la asociación de Cornellà. Alguna gente lo habla... No hay clase trabajadora catalanohablante, todos hablan castellano. La gente con quien hablo catalán es de clase media: jóvenes, estudiantes... [TPC]

El caso de A4H20 es interesante, dado que su hermano mayor y él entran en la categoría efecto espejo, pero sus hermanos pequeños no. Esto es debido a que él y su hermano fueron a una escuela donde se habla más catalán y los hermanos pequeños a frecuentaron una escuela diferente donde se habla más castellano. El contacto con el catalán, pues, habría actuado como desencadenante para el efecto espejo, por el que él y su hermano usan el catalán como lengua preferente y se identifican como catalano-amazigh:

A4H20: Pues el [hermano] mayor y yo somos quienes hablamos más en catalán, los que tenemos vida en catalán, y los otros más en castellano. Con sus amigos... [hablan] en castellano. Desde que [vivíamos en] Sant Andreu [barrio de Barcelona], sí, porque esto viene diferenciado porque yo estudiaba en un instituto en el que había gente más catalana y ellos habían estudiado en una escuela más castellanohablante, y esto desde un principio ya se va notando. [TPC]

Finalmente, la consciencia pro-amazigh que ya habían desarrollado en Marruecos de los participantes del primer grupo hizo que sus ideologías y actitudes hacia el catalán una vez en Cataluña fueran positivas desde un primer momento. Sin embargo, es de destacar que la gran mayoría de participantes desconocían la existencia del catalán antes de emigrar. En detalle, se identifican como amazigh y catalanes y usan el catalán como lengua preferente. Además, luchan para visibilitzar y mantener la lengua y cultura amazigh en Cataluña. A6H40 explica el proceso por el que pasan muchos amazigh: 
A6H40: Sí que hay gente que antes no pensaba en esto, que fue cuando llegaron aquí, en la sociedad de acogida... se reconocen, se dan importancia, y esto provoca un poco de choque. [TPC]

A2H40 cuenta cómo se dio cuenta de su identidad al mudarse de la zona rural amazigh a la zona urbana árabe:

A2H40: Pero la consciencia más fuerte comenzó en la universidad. Allí me encontré con la fracción amaziguista. [...]

Después me di cuenta ya aquí que estás en tu país, tu tierra, y te están negando lo tuyo, iy te tienes que rendir al discurso dominante! [TPC]

4.1.3. El efecto espejo: construcción de una escala para su observación

Hemos visto distintos ejemplos y tipologías del efecto espejo. A partir de los datos obtenidos, se ha elaborado una escala de 3 fases que llevan al efecto espejo. Se han diferenciado estas fases porque se cree que las ideologías lingüísticas de miembros de comunidades minorizadas pueden explicarse bien de acuerdo con la fase en la que se encuentren.

0) Identificar paralelismos entre el catalán y la lengua minorizada propia. Transposición unidireccional.

1) Cambio de representaciones e ideologías lingüísticas -reino ideológico de Fishman (1991: 114). Transposición bidireccional.

2) Cambio de prácticas lingüísticas, activismo lingüístico y cultural (acción). Transposición bidireccional.

Se ha definido a la primera fase "Fase 0 " porque es común a todos los participantes. En otras palabras, todos los participantes han establecido o encontrado paralelismos entre su comunidad minorizada y la comunidad de acogida. Ante estos paralelismos, han analizado la situación de la comunidad de acogida con la interpretación de la sociedad de origen, lo que hemos llamado 'transposición unidireccional'.

La Fase 1 implica un cambio en el mundo ideológico, pero no implica compromiso ni acción que responda a este cambio ideológico. En esta fase podemos incluir a muchos participantes quechua. Estos son casos potenciales de efecto espejo, frenado por distintos factores. En esta fase ya encontramos una transposición bidireccional, es decir, el cambio de representaciones lingüísticas ocurrido en la sociedad de acogida provoca una reinterpretación del análisis sociolingüístico de la sociedad de origen.

Lengua y migración / Language and Migration 12:1 (2020) Monográfico, 127-173

Edición impresa: ISSN 1889-5425. Edición en línea: ISSN 2660-7166. @ U Universidad de Alcalá 
Así, por ejemplo, el participante Q4H50 fue profesor de quechua en Ecuador y es un caso claro de Fase 1. Después de emigrar a Cataluña, ha estado haciendo trabajos de baja calificación. Ve paralelismos con la situación catalana, y ha aprendido algo de catalán y dice querer practicarlo más a pesar de no usarlo. Además, le gustaría que en Ecuador se implementaran políticas lingüísticas similares a las de Cataluña, y también le gustaría estar implicado en actividades culturales quechua. Los perfiles de Q1D45 y Q2H45 también se adecúan a esta fase.

Sólo hablamos de efecto espejo en la Fase 2. Esta fase implica, por una parte, una transposición bidireccional, igual que en la Fase 1, por otra, compromiso y acción. Es decir, un cambio no solo en las ideologías lingüísticas sino también en las prácticas lingüísticas, como por ejemplo las mudas lingüísticas (Pujolar y Puigdevall 2015). Así pues, los casos analizados y tratados como efecto espejo se adecúan a la Fase 2.

\subsection{Análisis de los datos cuantitativos. Las ideologías lingüísticas}

Las ideologías lingüísticas se analizarán usando los datos cuantitativos como base, complementados con los datos cualitativos y el trabajo de otros autores. Los datos cuantitativos son esenciales para describir las ideologías lingüísticas, pero especialmente para poder generalizar los resultados, estadísticamente hablando, a toda la comunidad.

\subsubsection{Perfil de los participantes}

Las siguientes tablas muestran el perfil de los participantes en los cuestionarios.

Participantes quechua (34 participantes)

Las siguientes tablas muestran el perfil sociodemográfico de los participantes quechua según las variables sexo, edad, país de origen, nacionalidad con la que más identifican, profesión, trayectoria educativa, lengua materna y competencias lingüísticas. 


\begin{tabular}{|l|r|}
\hline \multicolumn{2}{|c|}{ Sexo } \\
\hline Mujer & 23 \\
\hline Hombre & 11 \\
\hline
\end{tabular}

Tabla 2. Sexo de los participantes quechua

Como se puede apreciar en la Tabla 2, hay una sobrerepresentación de mujeres en la muestra de participantes.

\begin{tabular}{|l|r|}
\hline \multicolumn{2}{|c|}{ Edad } \\
\hline $15-19$ & 17 \\
\hline $20-24$ & 16 \\
\hline $25-29$ & 5 \\
\hline $30-34$ & 1 \\
\hline $35-39$ & 2 \\
\hline $40-44$ & 3 \\
\hline $45-49$ & 2 \\
\hline $50-54$ & 1 \\
\hline $55-59$ & 1 \\
\hline $60-64$ & 0 \\
\hline $65-70$ & 0 \\
\hline
\end{tabular}

Tabla 3. Edad de los participantes quechua

En la Tabla 3 vemos que todas las generaciones están representadas, excepto los participantes de entre 20 y 30 años de edad, mientras que en la Tabla 4 se aprecia que la mayoría de participantes son de Bolivia y Perú.

\begin{tabular}{|l|r|}
\hline \multicolumn{2}{|c|}{ País de origen } \\
\hline Argentina & 3 \\
\hline Bolivia & 13 \\
\hline Ecuador & 6 \\
\hline España & 1 \\
\hline Perú & 10 \\
\hline Chile & 1 \\
\hline
\end{tabular}

Tabla 4. País de origen de los participantes quechua

Como muestra la Tabla 5, la identificación nacional de los participantes quechua de las encuestas es muy diversa. Solo tres de los encuestados declaran tener una identidad nacional catalana, mientras que 11 se sienten españoles. La gran mayoría mantiene la identidad nacional del país o región (andina) de origen.

Lengua y migración / Language and Migration 12:1 (2020) Monográfico, 127-173

Edición impresa: ISSN 1889-5425. Edición en línea: ISSN 2660-7166. @ Universidad de Alcalá 


\begin{tabular}{|l|r|}
\hline \multicolumn{2}{|c|}{ Nacionalidad con la que se identifica más } \\
\hline Americana & 2 \\
\hline Argentina & 1 \\
\hline Argentina y países andinos & 1 \\
\hline Países andinos & 1 \\
\hline Boliviana & 6 \\
\hline Boliviana y española & 4 \\
\hline Catalana & 1 \\
\hline Catalana y boliviana & 1 \\
\hline Catalana, italiana y alemana & 1 \\
\hline Ecuatoriana & 3 \\
\hline Ecuatoriana y española & 3 \\
\hline Española & 2 \\
\hline Española, argentina, peruana y boliviana & 1 \\
\hline Peruana & 2 \\
\hline Peruana y española & 4 \\
\hline
\end{tabular}

Tabla 5. Nacionalidad de identificación de los participantes quechua

\begin{tabular}{|l|r|}
\hline \multicolumn{2}{|c|}{ Trayectoria educativa } \\
\hline Escuela primaria (hasta 12 años) & 3 \\
\hline Escuela secundaria (hasta 16 años) & 8 \\
\hline Escuela secundaria (hasta 18 años) & 8 \\
\hline Universidad & 15 \\
\hline
\end{tabular}

Tabla 6. Trayectoria educativa de los participantes quechua

La Tabla 6 enseña que el nivel educativo de los participantes quechua de las encuestas es alto, mientras que la Tabla 7 muestra que el nivel educativo no se correlaciona con la profesión, ya que la mayoría de profesiones no requieren de una educación universitaria. 


\begin{tabular}{|l|r|}
\hline \multicolumn{2}{|c|}{ Profesión } \\
\hline Lingüista & 1 \\
\hline Comerciante & 1 \\
\hline Profesor, operador de fábrica & 1 \\
\hline Geriatría y auxiliar de odontología & 2 \\
\hline Administrativo & 4 \\
\hline Mujer de la limpieza & 2 \\
\hline Arquitecta & 7 \\
\hline Estudiante & 1 \\
\hline Infermera & 1 \\
\hline Masagista, kinesióloga, reiki & 4 \\
\hline Profesor & 1 \\
\hline Electricista & 3 \\
\hline Dependienta & 1 \\
\hline Paleta & 2 \\
\hline Técnico de sanidad pública & 1 \\
\hline Músico, dependiente & 1 \\
\hline Artesano téxtil & 1 \\
\hline
\end{tabular}

Tabla 7. Profesión de los participantes quechua

La Tabla 8 muestra la lengua materna que los participantes quechua declaran tener. Es significativo que un tercio de los participantes no tienen el quechua como lengua materna.

\begin{tabular}{|l|r|}
\hline \multicolumn{2}{|c|}{ Lengua materna } \\
\hline Castellano & 11 \\
\hline Castellano y quechua & 14 \\
\hline Quechua & 7 \\
\hline
\end{tabular}

Tabla 8. Lengua materna de los participantes quechua

La Tabla 9, por último, indica las competencias lingüísticas que los participantes declaran tener. Es de destacar que hay una competencia de catalán muy baja entre los participantes, y que el castellano, al contrario que el quechua, es dominado por todos ellos. 


\begin{tabular}{|l|r|r|r|r|}
\hline \multicolumn{5}{|c|}{ Competencias lingüísticas } \\
\hline & Quechua & Castellano & \multicolumn{1}{|c|}{ Catalán } & \multicolumn{1}{|c|}{ Otros } \\
\hline Sé algunas palabras & 11 & 0 & 9 & 4 \\
\hline Puedo tener conversaciones básicas & 5 & 0 & 12 & 2 \\
\hline Me puedo comunicar con algunas dificultades & 5 & 0 & 5 & 6 \\
\hline Me puedo comunicar sin problemas & 3 & 8 & 7 & 1 \\
\hline Soy nativo/a & 10 & 26 & 0 & 0 \\
\hline
\end{tabular}

Tabla 9. Competencias lingüisticas de los participantes quechua

Participantes amazigh (48 participantes)

\begin{tabular}{|l|r|}
\hline \multicolumn{2}{|c|}{ Sexo } \\
\hline Mujer & 36 \\
\hline Hombre & 12 \\
\hline
\end{tabular}

Tabla 10. Sexo de los participantes amazigh

Al igual que entre los participantes quechua, las mujeres están también sobrerrepresentadas en la muestra de participantes amazigh, tal y como indica la Tabla 10. En cambio, a diferencia de la muestra de participantes quechua, en lo que atañe a la edad la sobrerrepresentación es de participantes jóvenes (15-29 años), como se aprecia en la tabla 22 (Anexo).

\begin{tabular}{|l|r|}
\hline \multicolumn{2}{|c|}{ Edad } \\
\hline $15-19$ & 17 \\
\hline $20-24$ & 16 \\
\hline $25-29$ & 5 \\
\hline $30-34$ & 1 \\
\hline $35-39$ & 2 \\
\hline $40-44$ & 3 \\
\hline $45-49$ & 2 \\
\hline $50-54$ & 1 \\
\hline $55-59$ & 1 \\
\hline $60-64$ & 0 \\
\hline $65-70$ & 0 \\
\hline
\end{tabular}

Tabla 11. Edad de los participantes amazigh 
La gran mayoría de los participantes amazigh han nacido en Marruecos, pero una proporción significante ha nacido en el estado español (ver Tabla 12). Ello tiene relación con el gran número de participantes jóvenes en la muestra. Es de destacar que no hay ningún participante nacido en Argelia.

\begin{tabular}{|l|r|}
\hline \multicolumn{2}{|c|}{ País de origen } \\
\hline España & 18 \\
\hline Marruecos & 29 \\
\hline Bélgica & 1 \\
\hline
\end{tabular}

Tabla 12. País de origen de los participantes amazigh

Según la Tabla 13, la mayoría de participantes se identifica con la adscripción nacional del estado-nación de origen, Marruecos o España. Hay pocas identificaciones con la nacionalidad amazigh o catalana. Hay un caso en el que se remarca que la identidad musulmana es la más importante para ese participante.

\begin{tabular}{|l|r|}
\hline \multicolumn{2}{|c|}{ Nacionalidad con la que más se identifica } \\
\hline Amazigh & 1 \\
\hline Amazigh y catalana & 2 \\
\hline Catalana & 2 \\
\hline Española & 11 \\
\hline Española y marroquí & 11 \\
\hline "Las dos" & 2 \\
\hline Marroquí & 15 \\
\hline Marroquí y amazigh & 1 \\
\hline "Qué drama. Gibraltar." & 1 \\
\hline Marroquí, rifiya y española & 1 \\
\hline Árabe y musulmana "(el islam es una identidad)" & 1 \\
\hline
\end{tabular}

Tabla 13. Nacionalidad de identificación de los participantes amazigh

En las Tablas 14 y 15 también se puede observar esa sobrerrepresentación de menores de 25 años en la muestra de participantes.

\begin{tabular}{|l|r|}
\hline \multicolumn{2}{|c|}{ Trayectoria educativa } \\
\hline Escuela primaria (hasta 12 años) & 0 \\
\hline Escuela secundaria (hasta 16 años) & 7 \\
\hline Escuela secundaria (hasta 18 años) & 13 \\
\hline Universidad & 28 \\
\hline
\end{tabular}

Tabla 14. Trayectoria educativa de los participantes amazigh

Lengua y migración / Language and Migration 12:1 (2020) Monográfico, 127-173 Edición impresa: ISSN 1889-5425. Edición en línea: ISSN 2660-7166. @ Universidad de Alcalá 


\begin{tabular}{|l|r|}
\hline \multicolumn{2}{|c|}{ Profesión } \\
\hline Ninguna & 4 \\
\hline Cocinero & 17 \\
\hline Estudiante & 1 \\
\hline Paleta & 4 \\
\hline Administrador & 2 \\
\hline Profesor & 1 \\
\hline Ingeniero & 1 \\
\hline Abogado & 2 \\
\hline Dependiente & 1 \\
\hline Pedagogo & 2 \\
\hline Eduacador & 1 \\
\hline Educador y mediador & 2 \\
\hline Mujer de negocios & 1 \\
\hline Intérprete & 2 \\
\hline Trabajador temporal & 1 \\
\hline Funcionario y mediador & 1 \\
\hline Informático & 1 \\
\hline Trabajador social & 1 \\
\hline Recepcionista & 1 \\
\hline
\end{tabular}

Tabla 15. Profesión de los participantes amazigh

Al contrario que con la comunidad quechua, la Tabla 16 enseña como el amazigh es la lengua materna de la gran mayoría de los participantes, pese a haber nacido en Cataluña.

\begin{tabular}{|l|r|}
\hline \multicolumn{2}{|c|}{ Lengua materna } \\
\hline Amazigh & 31 \\
\hline Amazigh and Catalan & 2 \\
\hline Amazigh and Arabic & 5 \\
\hline Amazigh and Spanish & 3 \\
\hline Catalan & 1 \\
\hline French and Arabic & 1 \\
\hline Spanish, Catalan and Amazigh & 2 \\
\hline Arabic & 1 \\
\hline Spanish, Arabic and Amazigh & 1 \\
\hline Arabic, Amazigh, Catalan and Spanish & 1 \\
\hline
\end{tabular}

Tabla 16. Lengua materna de los participantes amazigh

Finalmente, las competencias lingüísticas de los participantes amazigh son muy altas tanto para las dos lenguas dominantes (castellano y

Lengua y migración / Language and Migration 12:1 (2020) Monográfico, 127-173 Edición impresa: ISSN 1889-5425. Edición en línea: ISSN 2660-7166. @ Universidad de Alcalá 
árabe) como para las dos lenguas subordinadas (amazigh y catalán). Así, la mayoría de participantes son multilingües, cosa que no podemos afirmar para los participantes quechua.

\begin{tabular}{|l|r|}
\hline \multicolumn{2}{|c|}{ Lengua materna } \\
\hline Amazigh & 31 \\
\hline Amazigh and Catalan & 2 \\
\hline Amazigh and Arabic & 5 \\
\hline Amazigh and Spanish & 3 \\
\hline Catalan & 1 \\
\hline French and Arabic & 1 \\
\hline Spanish, Catalan and Amazigh & 2 \\
\hline Arabic & 1 \\
\hline Spanish, Arabic and Amazigh & 1 \\
\hline Arabic, Amazigh, Catalan and Spanish & 1 \\
\hline
\end{tabular}

Tabla 17. Competencias lingüisticas de los participantes amazigh

El perfil de los participantes en las encuestas condiciona las respuestas y explica los posibles sesgos. La desproporcionalidad más evidente es la del sexo: hay una mayor proporción de mujeres en las dos comunidades. La segunda es la edad: mientras que la edad de los participantes quechuas coincide con los participantes de las entrevistas semiestructuradas (mayoría de adultos de primera generación), en el caso de los participantes amazigh no coincide. Por un lado, en las encuestas hay una sobrerrepresentación de jóvenes, muchos de ellos de segunda generación o de generación 1.5 -personas migradas antes de la mayoría de edad-; por otro, los participantes de las entrevistas son mayoritariamente adultos de primera generación. El factor edad también influye en las variables "trayectoria educativa" y "profesión".

La identidad de los quechuas es mayoritariamente americana -de su estado-nación-, panamericana o panandina. También hay referencias a una identidad española y unas pocas a una identidad catalana. Los amazigh tienen más variabilidad de respuestas y algunos participantes manifestaron problemas para definir su identidad. Esta dificultad está relacionada con el hecho de que la mayoría de participantes son de segunda generación. Las respuestas presentan un número de referencias significativas a la identidad española, a la identidad catalana pero también a la identidad islámica o musulmana, además de referencias al estado-nación-Marruecos-, y a una identidad amazigh -con la variación de endónimos correspondiente, por ejemplo "rifiya" (amazigh del Rif). 
Como se puede observar a partir de los Gráficos 8 y 16, el 34\% de los participantes quechuas no declaran el quechua como su lengua materna y dos tercios de los que sí que la declaran lo hacen al lado del castellano. Por otro lado, más del $90 \%$ de los amazigh, incluso los de segunda generación, declaran el amazigh como lengua materna (en diferentes combinaciones). Las competencias lingüísticas también difieren mucho: los quechuas declaran un dominio nativo del castellano, con diferencias significativas respecto a las demás lenguas y suelen declarar tener un dominio básico de quechua y de catalán. La comunidad amazigh, por el contrario, posee muy altas competencias en amazigh y castellano y altas competencias en catalán, mayores que en árabe.

\subsubsection{Resultados de las encuestas}

Los siguientes gráficos muestran los resultados de las preguntas de escala de Likert sobre ideologías lingüísticas por comunidad. Para analizar los resultados de las encuestas, se deben tener en cuenta los sesgos ya descritos sobre la naturaleza de la investigación cuantitativa (Foddy, 1997; Low, 1999), discutidos en la metodología y las particularidades sobre la muestra.

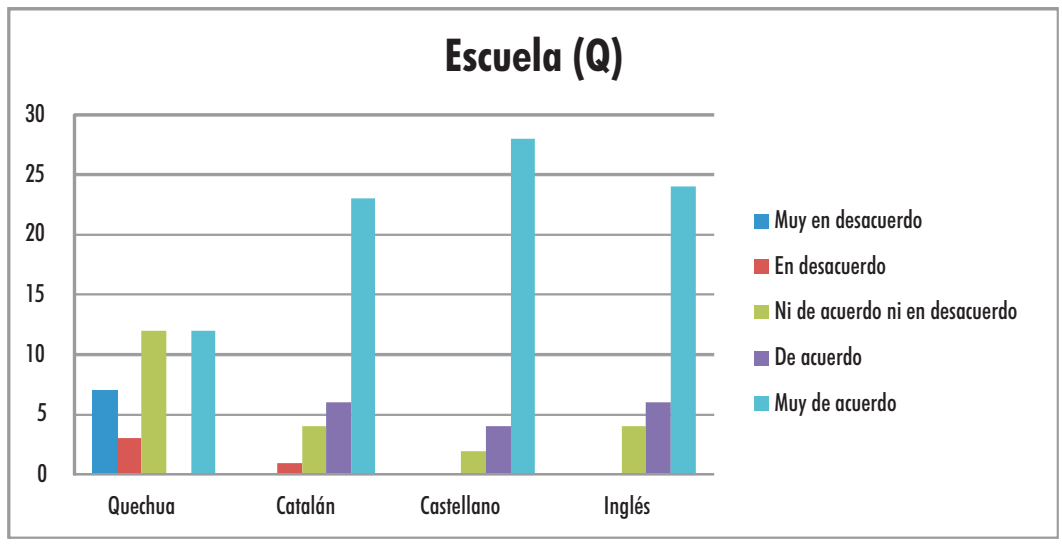

Gráfico 1. Importancia de las lenguas en la escuela para los participantes quechua

Los Gráficos 1 y 2 responden a la pregunta de si las lenguas son importantes en la escuela del país de acogida. Las dos comunidades valoran la lengua propia en parámetros similares. En el caso de la comunidad amazigh, el árabe es percibido como igual de importante en la escuela que el amazigh. El catalán, castellano e inglés son las más 
importantes para las dos comunidades, aunque el castellano sea percibido como más importante por los quechua y el inglés lo sea para los amazigh. Cuando son preguntados en las entrevistas, a algunos quechua sí que les gustaría que se incluyera su lengua en el currículum extraescolar:

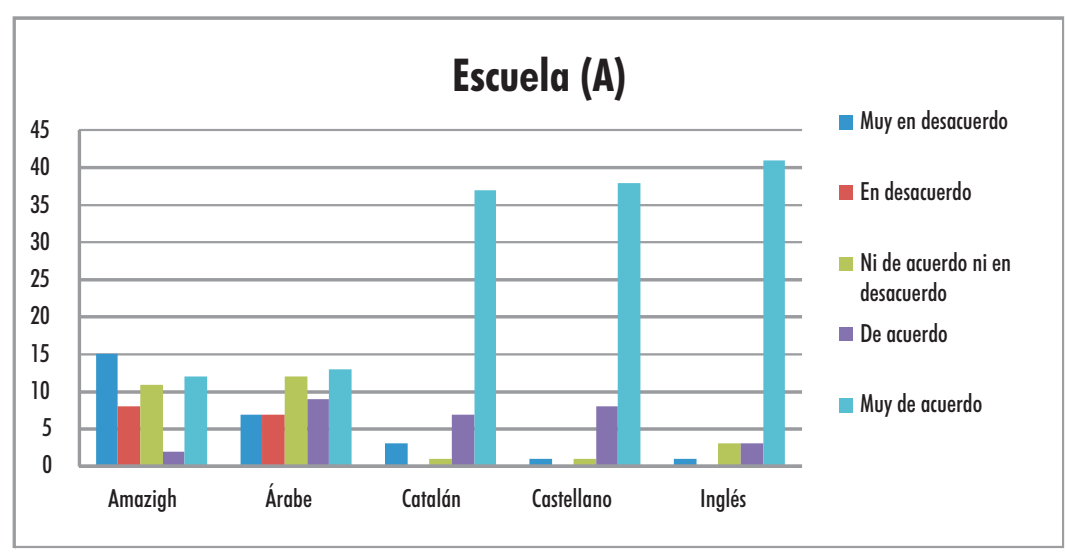

Gráfico 2. Importancia de las lenguas en la escuela para los participantes amazigh

Q4H50: Hicimos una asociación de profesores ecuatorianos, nos reuníamos y hablábamos en kichwa y en castellano, algunos no sabían kichwa pero los otros les enseñamos. Cuando di la charla había mucha gente interesada en clases de kichwa, pero por mi trabajo es complicado y no terminamos de concretar los cursos.

A la comunidad amazigh también le gustaría que hubiera más recursos para enseñar amazigh a los niños. A su vez aceptan mayormente el sistema de inmersión lingüística en catalán y se quejan que haya muchos más recursos para clases de árabe, como manifiesta $\mathrm{A} 2 \mathrm{H} 40$ :

A2H40: Se están dando clases a 4 grupos: Sabadell, Terrassa, Manresa y Montcada. Pero es muy poco. Si comparas enseñanza de amazigh y de árabe, todos se hacen en horario extraescolar, pero hay muchos profesores de árabe. Marruecos paga y forma una bolsa de profesores de árabe para los hijos de los marroquíes en Cataluña. Pero ni un profesor amazigh. El Parlamento [de Cataluña] se comprometió... pero al final nada de nada. [TPC]

Los resultados de las preguntas sobre la importancia de las lenguas en el trabajo (Gráficos 3 y 4 ) son parecidos con los resultados sobre la escuela, ya que tienen que ver con la utilidad de las lenguas en la sociedad de acogida y con el concepto de anonimidad de Woolard (2008: 304-306).

Lengua y migración / Language and Migration 12:1 (2020) Monográfico, 127-173

Edición impresa: ISSN 1889-5425. Edición en línea: ISSN 2660-7166. @ Universidad de Alcalá 


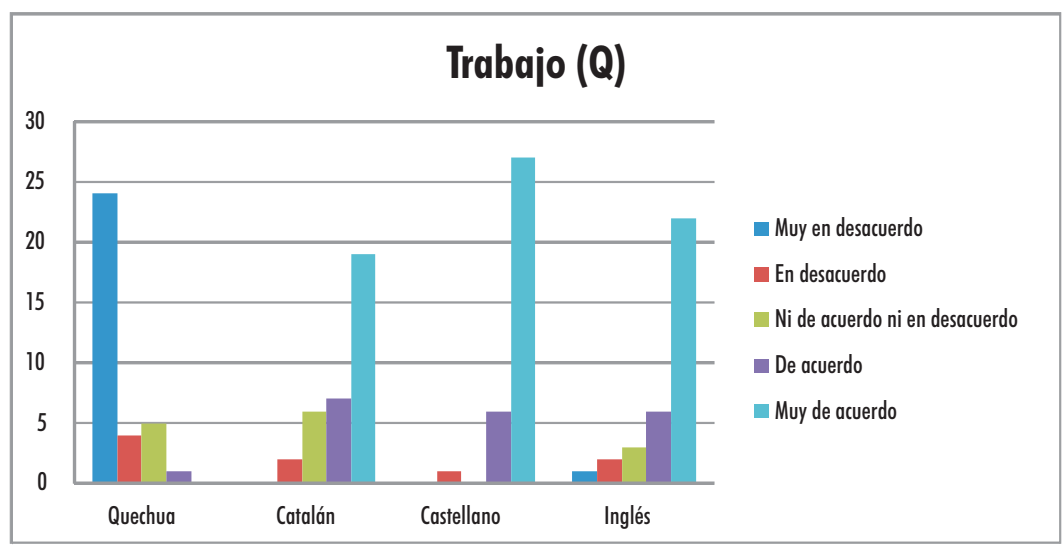

Gráfico 3. Importancia de las lenguas en el trabajo para los participantes quechua

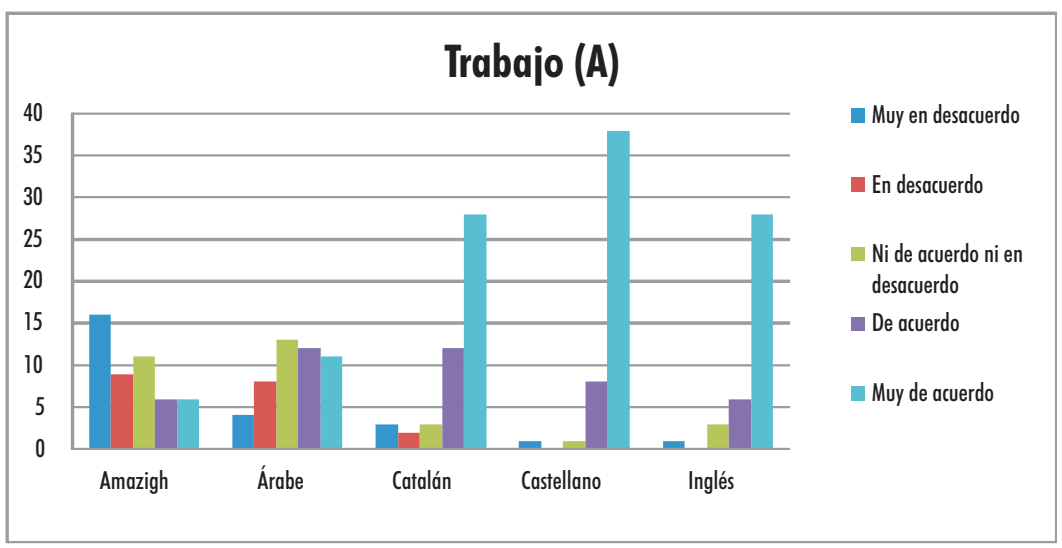

Gráfico 4. Importancia de las lenguas en el trabajo para los participantes amazigh

Los quechuas valoran el catalán, el castellano y el inglés muy positivamente, pero consideran que el quechua no es importante. Los amazigh coinciden en las valoraciones de la importancia del catalán, el castellano y el inglés, pero están más de acuerdo que los quechuas en que su lengua propia sea importante para trabajar, con una valoración similar a la que recibe el árabe. Esto se explica por el hecho que algunos participantes lo usan para comunicarse, tanto en el trabajo como fuera de él. Los participantes reportan usar amazigh y árabe en el sector obrero o en el sector de servicios sociales. En cambio, ningún participante ha reportado el uso de quechua en el lugar de trabajo.

Lengua y migración / Language and Migration 12:1 (2020) Monográfico, 127-173 Edición impresa: ISSN 1889-5425. Edición en línea: ISSN 2660-7166. @ Universidad de Alcalá 
A2H40: Trabajo en un centro de menores. Allí, en mis relaciones laborales con los compañeros de trabajo hablamos tres lenguas y a veces hasta en francés con un chico senegalés. Hablo catalán con algunos jóvenes, porque quieren, también. También con compañeros educadores. También castellano con otros educadores y chicos que tienen más tendencia a hablar en castellano. Y a veces el darija, con dos personas sobretodo. Y también amazigh, hay un compañero amazigh y algunos chicos también. La lengua dominante es el catalán. Toda la documentación por escrito es en catalán. [TPC]

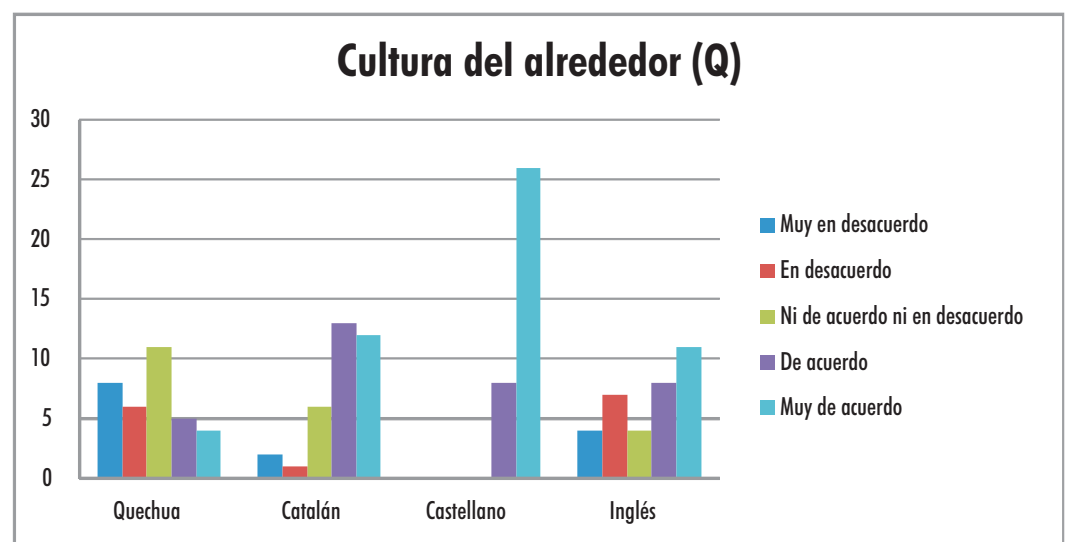

Gráfico 5. Importancia de las lenguas en la cultura del alrededor para los participantes quechua

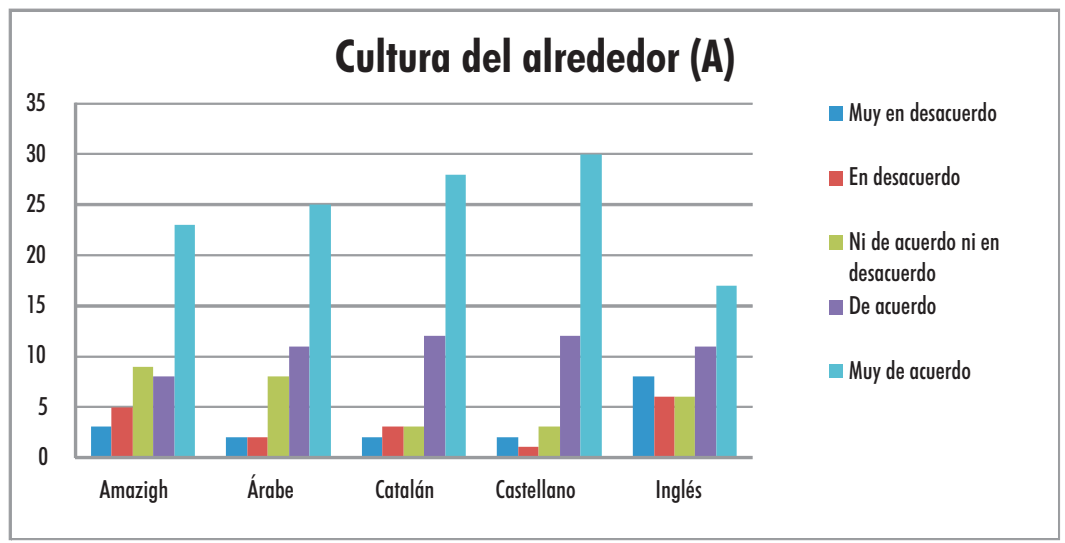

Gráfico 6. Importancia de las lenguas en la cultura del alrededor para los participantes amazigh

Los Gráficos 5 y 6 muestran los resultados de la pregunta sobre la importancia de las lenguas en el entorno cultural del país de acogida, en

Lengua y migración / Language and Migration 12:1 (2020) Monográfico, 127-173

Edición impresa: ISSN 1889-5425. Edición en línea: ISSN 2660-7166. @ Universidad de Alcalá 
los que hay diferencias significativas entre las dos comunidades. El catalán recibe mayormente una valoración positiva, pero menos positiva que en comparación con el castellano, que unánimemente es considerado como una lengua importante. Es de destacar que el inglés recibe una valoración más positiva que el quechua. Los quechua no consideran su lengua propia importante para el entorno cultural de su día a día, hecho significativo e indicativo de la ocultación generalizada de la lengua quechua en la sociedad, ocultación que se da tanto en América como en Europa (problematizado en Comellas et al. 2010).

Q4H50: No... lo que pasa es que a veces la misma gente nuestra es la que... no nos damos el valor que nos tenemos que dar. Por ejemplo, si yo hablo kichwa, ¿por qué tengo que tener vergüenza de hablar? Lo que pasa es que mucha gente en Barcelona, gente de mi país, a veces son más indígenas que yo. Pero como están aquí como que aparentan. Dicen que no saben hablar. Ese perjuicio tiene la gente, de querer decir que sólo hablan castellano y que no son indígenas.

La comunidad amazigh, por el contrario, generalmente sí que considera la lengua propia, así como el árabe, importantes para el entorno cultural en Cataluña, y en este caso son valoradas como más importantes que el inglés. El catalán, a diferencia que para los quechuas, tiene una valoración significativamente positiva y muy parecida con la valoración del castellano. Este hecho guarda relación con el conocimiento de catalán de las dos comunidades y el hecho que la lengua dominante para los quechua sea la misma que para Cataluña.

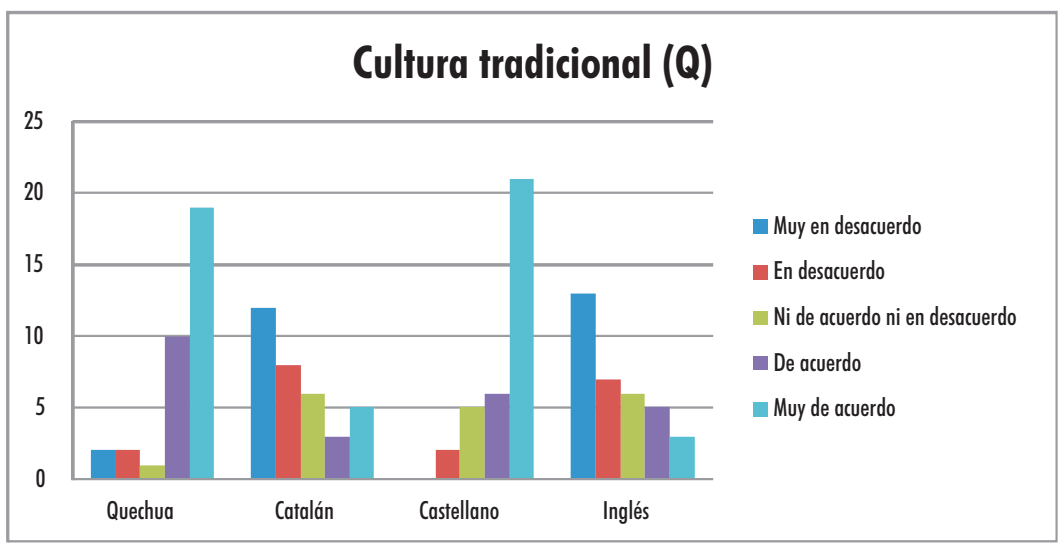

Gráfico 7. Importancia de las lenguas en la cultura tradicional para los participantes quechua 


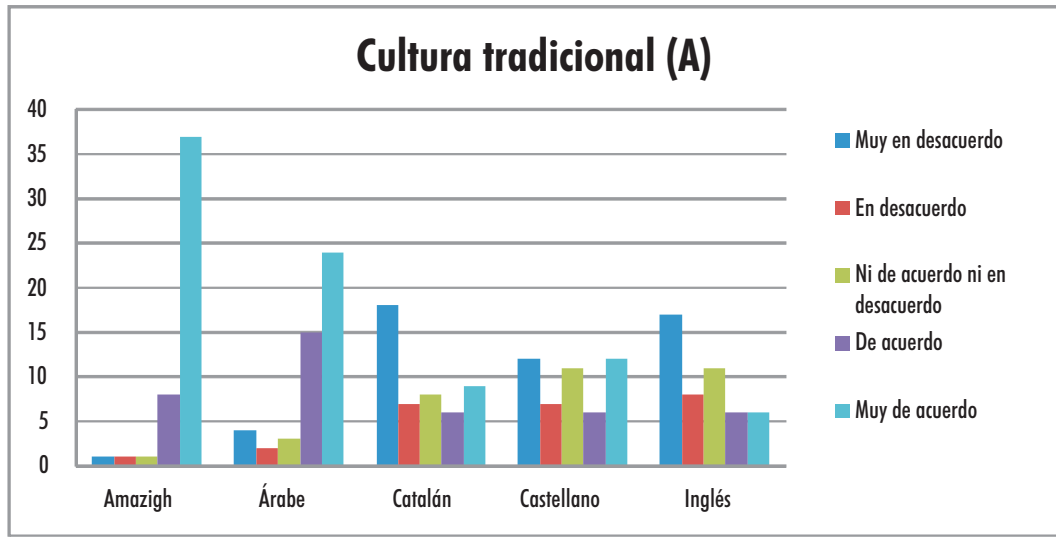

Gráfico 8. Importancia de las lenguas en la cultura tradicional para los participantes amazigh

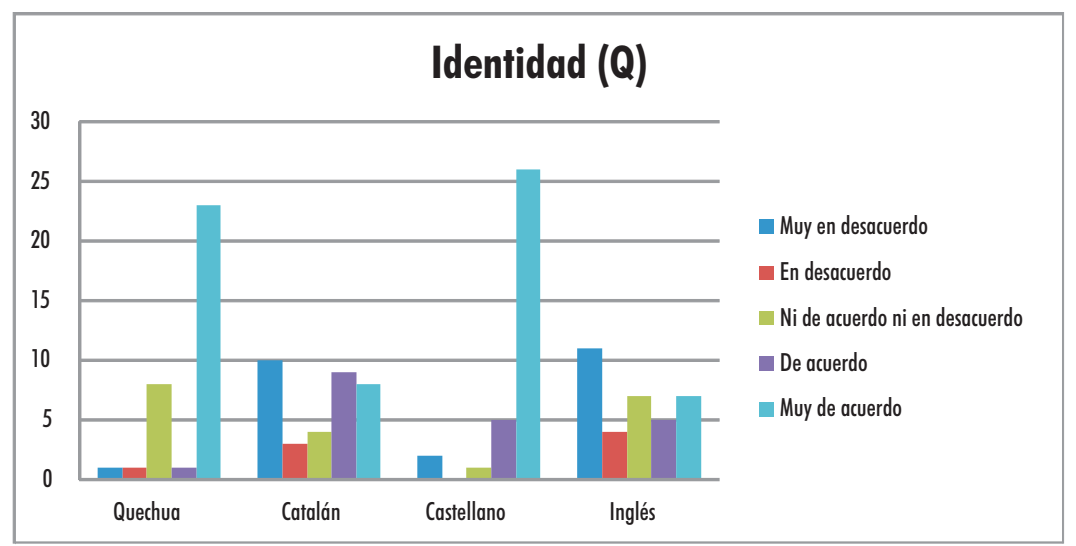

Gráfico 9. Importancia de las lenguas para la identidad para los participantes quechua

Las preguntas sobre la importancia de las lenguas para con la cultura tradicional son reflejadas en los Gráficos 7 y 8 . Las valoraciones de las lenguas propias de cada comunidad, consideradas importantes, guardan relación con el concepto de autenticidad de Woolard (2008: 304-306). Ambas comunidades valoran la lengua propia como importante para la identidad y el acceso a la cultura tradicional, aunque hay muchos quechuas que no hablan la lengua y a quien les resulta indiferente. Es de destacar, sin embargo, que la lengua dominante de los quechuas, el castellano, está más valorada que el quechua, mientras que la comunidad amazigh valora positivamente el árabe, pero con una diferencia con el amazigh. El catalán y el castellano están valorados neu-

Lengua y migración / Language and Migration 12:1 (2020) Monográfico, 127-173

Edición impresa: ISSN 1889-5425. Edición en línea: ISSN 2660-7166. @ Universidad de Alcalá 
tralmente para los amazigh, mientras que el catalán se valora como poco importante por los quechuas. El inglés tampoco les parece importante a ninguna de las dos comunidades.

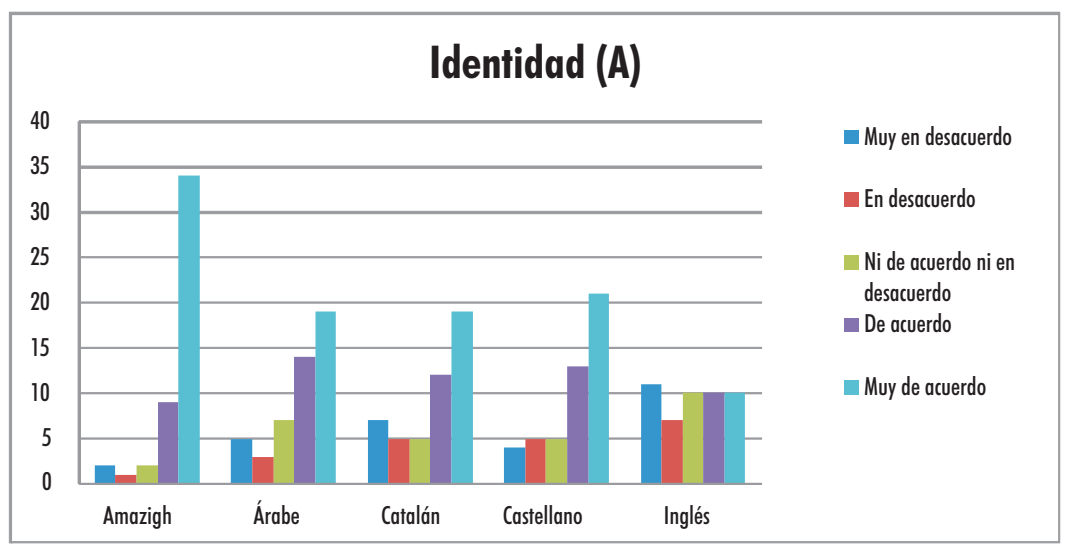

Gráfico 10. Importancia de las lenguas para la identidad para los participantes amazigh

De manera similar a la valoración de las lenguas en relación al acceso a la cultura tradicional de cada comunidad, los Gráficos 9 y 10 muestran unas valoraciones que remarcan el valor auténtico del quechua y el amazigh (Woolard 2008: 304-306). Los amazigh consideran el catalán y el castellano más importantes para la identidad que para la cultura tradicional, al mismo nivel que el árabe. El inglés es valorado otra vez como la lengua menos importante.

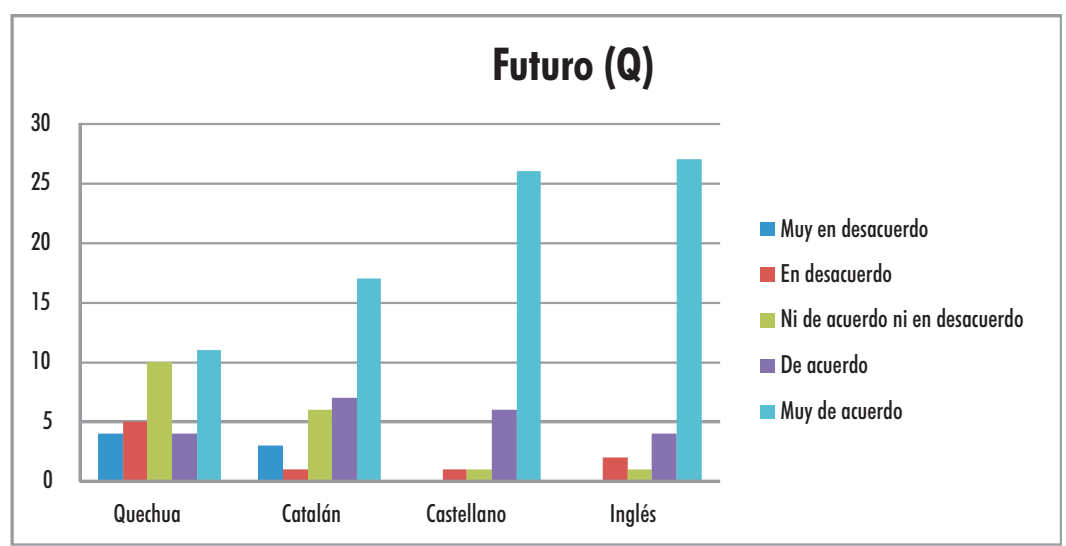

Gráfico 11. Importancia de las lenguas para el futuro para los participantes quechua

Lengua y migración / Language and Migration 12:1 (2020) Monográfico, 127-173 Edición impresa: ISSN 1889-5425. Edición en línea: ISSN 2660-7166. @ Universidad de Alcalá 
En el caso de la comunidad quechua, los resultados son muy iguales a los anteriores (Gráficos 7 y 8). El castellano vuelve a ser percibido como más importante que el quechua, con un rol de menor importancia para el catalán.

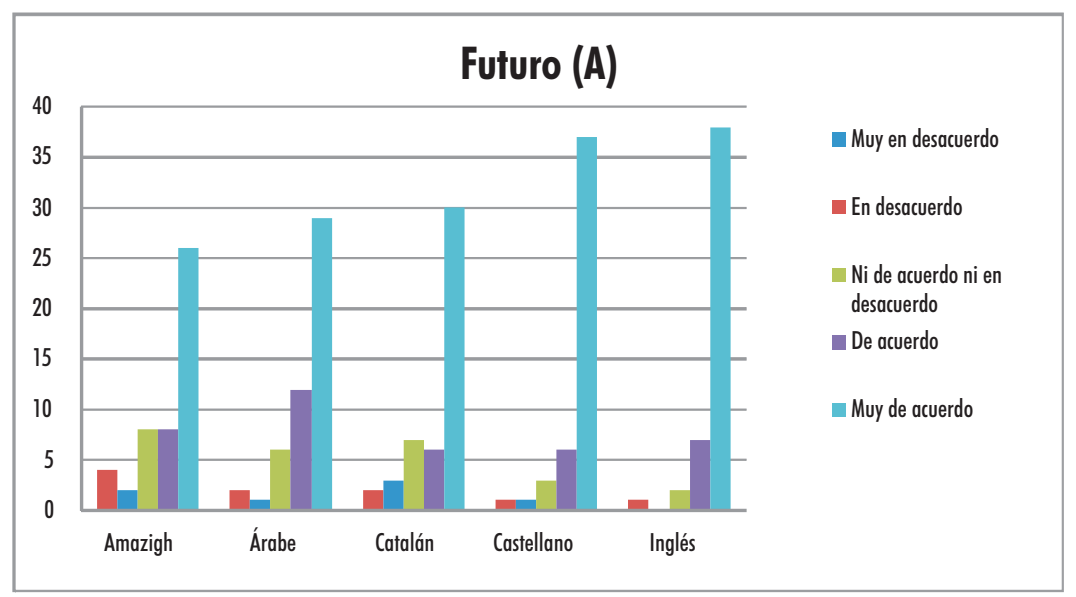

Gráfico 12. Importancia de las lenguas para el futuro para los participantes amazigh

En la pregunta sobre la importancia de las lenguas para el futuro de la descendencia (Gráficos 11 y 12), ambas comunidades señalan todas las lenguas como importantes, con algunas diferencias. Para los quechuas, el quechua es la menos importante, seguido del catalán en un segundo nivel, y con el inglés y el castellano como las más importantes en un primer nivel. La comunidad amazigh, por lo contrario, valora todas las lenguas muy positivamente, con una valoración del castellano y el inglés ligeramente más positiva que las demás lenguas. En las entrevistas se preguntó a los participantes si creían que las lenguas amenazadas por las que se preguntaba -catalán y quechua o amazigh- podrían llegar a desaparecer en Cataluña. Los participantes respondieron mayoritariamente que esta situación no podía llegar a pasar. Lo que vemos, sin embargo, es que la transmisión de las lenguas de herencia, como se ha abordado en la introducción, no está garantizada y, contrariamente a la percepción de los hablantes, tiende a romperse. Esta situación se ve reflejada en estos dos fragmentos de entrevista:

Q3D50: En mi casa hablo quechua pero mis hijos no lo entienden. Bueno, sí entienden algo pero no quieren hablar.

Investigador: ¿Crees que [tus hijos] tienen vergüenza de hablarlo?

Q3D50: Sí, por vergüenza. Cuando les hablo en quechua me dicen "mamá, ¡qué haces!”. Dice que no entiende nada, y que hablar quechua es mucho trabajo.

Lengua y migración / Language and Migration 12:1 (2020) Monográfico, 127-173

Edición impresa: ISSN 1889-5425. Edición en línea: ISSN 2660-7166. @ U Universidad de Alcalá 
A8D40: Con los hijos hablo en amazigh. Siempre me responden en amazigh, excepto si hay algún término concreto que no conocen.

Con los padres se habla en amazigh. Pero sí que he notado que entre los jóvenes se habla en castellano o catalán. Bueno, es lo que hacen mis hijos, entre ellos hablan en catalán, nunca se hablan en amazigh. [TPC]

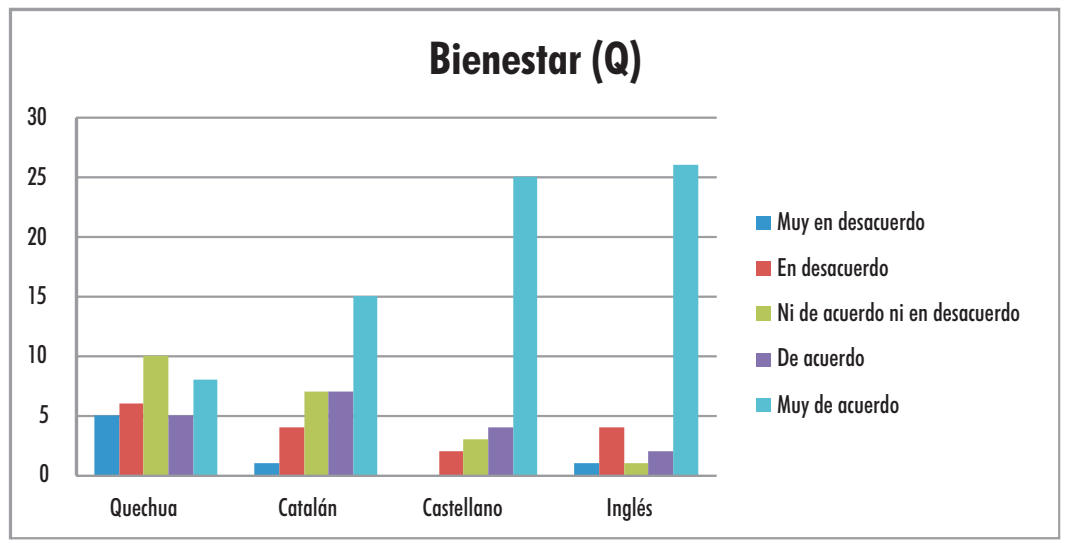

Gráfico 13. Importancia de las lenguas para el bienestar para los participantes quechua

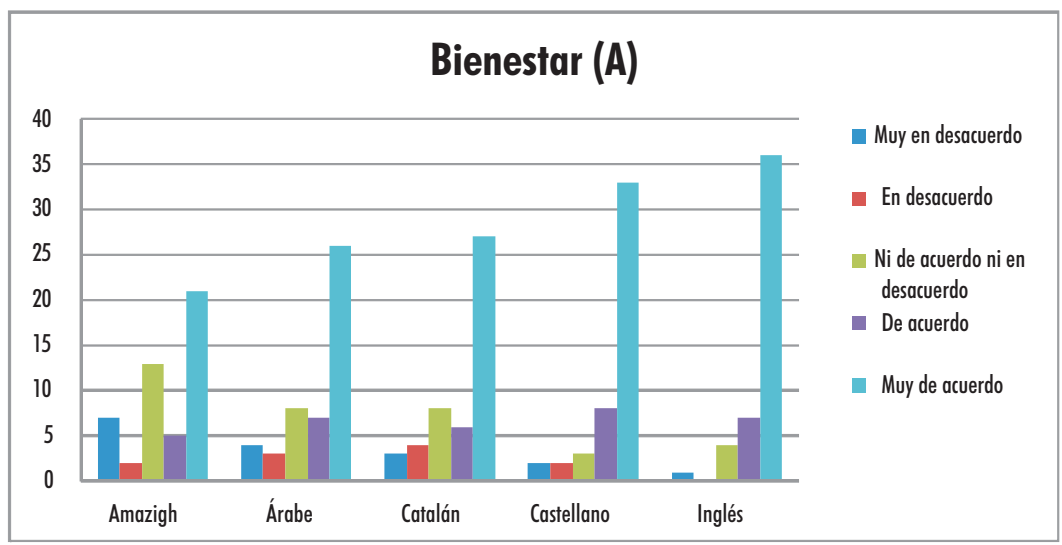

Gráfico 14. Importancia de las lenguas para el bienestar para los participantes amazigh

Finalmente, cabe destacar las grandes diferencias en la última pregunta sobre la importancia de las lenguas para el bienestar (Gráficos 13 y 14): por un lado, los quechuas no consideran su lengua propia importante para su bienestar, por otro, los amazigh sí que valoran la suya positivamente en este sentido. Igual que en la pregunta anterior 
(ver Gráficos 11 y 12), los quechuas valoran el catalán con puntuaciones neutrales, mientras que el castellano y el inglés reciben las valoraciones más positivas. Los participantes amazigh, como en la pregunta anterior, valoran positivamente todas las lenguas, con otra vez el castellano y el inglés un poco mejor valorados que el árabe, el catalán y el amazigh.

\subsubsection{Ideologías lingüísticas de los participantes}

A través de los resultados de las encuestas cuantitativas, combinados con las explicaciones dadas en las entrevistas cualitativas, podemos describir las ideologías lingüísticas de ambos grupos.

Los quechuas valoran sistemáticamente el castellano y el inglés por encima del catalán. Según las valoraciones, el catalán tiene poco valor identitario, mientras que el quechua tiene mucho valor identitario pero poco valor utilitario, dado que es valorado negativamente en todos los otros aspectos. El castellano, por el contrario, es bien valorado en todas las preguntas, siendo la lengua de facto de la comunidad. Usando la terminología de Woolard (2008), podríamos resumir que el quechua es una lengua claramente auténtica y el castellano y el inglés son claramente anónimas, con el catalán sin un rol claro para la sociedad quechua que lo habla y usa poco y no es valorado demasiado positivamente.

Los amazigh, por su lado, tienen tendencia a valorar todas las lenguas como importantes, excepto en las preguntas sobre identidad y cultura tradicional. El catalán y el árabe reciben valoraciones semejantes, y el castellano y el inglés tienden a ser las mejor valoradas en cuestiones de utilidad y futuro. El amazigh es una lengua bien valorada y, aunque menos útil que las demás, se considera la lengua principal de la comunidad. Estas ideologías se pueden ver reflejadas en este fragmento de entrevista:

Investigador: ¿Qué lenguas son importantes para tu identidad?

A1H45: El amazigh es la lengua más importante de todas para la identidad. El árabe no. Estoy contento de saberlo y me gusta hablarlo, pero solo es para comunicarse, no para la identidad. El castellano y el catalán son importantes también. El catalán más. Pero el amazigh es la más importante.

Investigador: ¿Qué lenguas son más útiles?

A1H45: Todas las lenguas son útiles. Amazigh, árabe, catalán, castellano, inglés, francés... Todas aportan alguna cosa. Cuantas más lenguas sabes, mejor. [TPC]

Las dos comunidades valoran el inglés como importante, al lado del castellano con valoraciones muy positivas, especialmente en lo que atañe

Lengua y migración / Language and Migration 12:1 (2020) Monográfico, 127-173

Edición impresa: ISSN 1889-5425. Edición en línea: ISSN 2660-7166. @ Universidad de Alcalá 
a utilidad. Algunos participantes puntuaron el inglés con 5 en todas las respuestas, incluidas las de identidad, con el argumento "el inglés es muy importante, se tiene que conocer". Sería muy interesante ver los resultados sin la opción de marcar el inglés, pero en todo caso lo que demuestra es que el inglés es una lengua presente en el paisaje lingüístico mental de las personas y que se tiene mucho en cuenta, además de ser valorada de forma muy parecida a la lengua dominante.

Así pues, los quechuas presentan ideologías lingüísticas que tienden al monolingüismo español y a la jerarquización de lenguas, sobre todo con criterios de utilidad, con un enorme peso de las lenguas dominantes -español e inglés. Hay cierta negatividad respecto la lengua propia y respecto el catalán, aunque esta última se reconoce como importante en ciertos sectores, como en la escuela.

Los amazigh, contrariamente, presentan unas ideologías lingüísticas más favorables al plurilingüismo, con una valoración positiva de todas las lenguas. Son también más multilingües: tienen más conocimiento de catalán y de la categoría "otras lenguas”, además de muchos de ellos conocer el árabe.

\section{Discusión}

Como hemos visto, el efecto espejo es un fenómeno complejo que afecta las representaciones, ideologías y actitudes lingüísticas de manera diferente dependiendo de la comunidad y de la trayectoria de cada individuo. En esta sección se explicará (1) cómo el efecto espejo moldea las ideologías lingüísticas, (2) qué factores influyen en la escala de fases del efecto espejo y (3) se compararán las ideologías lingüísticas de las comunidades minorizadas (quechua y amazigh) con las ideologías lingüísticas de los grupos dominantes (marroquíes y latinoamericanos).

\subsection{Efecto espejo en relación a las ideologías lingüísticas}

Hemos visto que el efecto espejo se da una vez el individuo emigra a un lugar con una situación sociolingüística similar a la del país de origen, lo que le hace revalorar y reanalizar sus percepciones sociolingüísticas y puede llevar a un cambio en las ideologías y prácticas lingüísticas. Las Tablas 18 y 19 detallan los cambios experimentados consecuencia del efecto espejo en las ideologías lingüísticas de los participantes de cada comunidad que han experimentado el efecto espejo. 


\begin{tabular}{|c|c|c|}
\hline Participante & Antes de emigrar a Cataluña & Después de emigrar a Cataluña \\
\hline Q5D40 & Consciencia e identidad quechuas & $\begin{array}{ll}\text { - } & \text { Activismo cultural quechua. } \\
\text { - } & \text { Sensibilidad hacia el catalán. } \\
\text { - } & \text { Identificación con la identidad } \\
& \text { catalana. }\end{array}$ \\
\hline Q6H50 & $\begin{array}{l}\text { Negación de la identidad y herencia } \\
\text { quechuas. }\end{array}$ & $\begin{array}{ll}\text { - } & \text { Redescubrimiento de la propia } \\
& \text { identidad quechua. } \\
\text { - } & \text { Activismo contra diversos tipos de } \\
\text { discriminación sociocultural. } \\
\text { - } \quad \text { Identificación parcial con la identidad } \\
\text { catalana. }\end{array}$ \\
\hline
\end{tabular}

Tabla 18. Efecto espejo en la comunidad quechua

Del mismo modo, la Tabla 19 resume los casos de efecto espejo entre la comunidad amazigh:

\begin{tabular}{|c|c|c|}
\hline Participantes & Antes de emigrar a Cataluña & Después de emigrar a Cataluña \\
\hline $\begin{array}{l}\mathrm{A} 2 \mathrm{H} 40 \mathrm{~A} 6 \mathrm{H} 40 \\
\mathrm{~A} 8 \mathrm{D} 40 \mathrm{~A} 9 \mathrm{H} 40\end{array}$ & Consciencia y activismo. & $\begin{array}{ll}\text { - } & \text { Identificación con la identidad } \\
& \text { catalana. } \\
\text { - } & \text { Identidad catalano-amazigh. } \\
\text { - } & \text { Catalán como lengua preferente. } \\
\text { - } & \text { Activismo amazigh. }\end{array}$ \\
\hline $\begin{array}{l}\text { AlH45 A3D20 } \\
\text { A4H2O }\end{array}$ & $\begin{array}{l}\text { Sin una clara consciencia de la } \\
\text { especificidad amazigh. }\end{array}$ & $\begin{array}{ll}\text { - } & \text { Descubrimiento e identificación de la } \\
\text { identidad amazigh propia. } \\
\text { - } \quad \text { Los mismos efectos que en grupo } \\
\text { previo. }\end{array}$ \\
\hline A7D40 & $\begin{array}{l}\text { Consciencia y curiosidad, pero no } \\
\text { compromiso. }\end{array}$ & 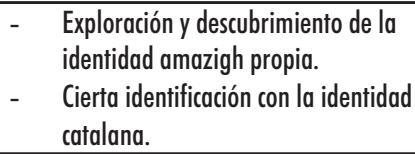 \\
\hline
\end{tabular}

Tabla 19. Efecto espejo en la comunidad amazigh

Aunque hay pocos participantes en los que se ha podido detectar y analizar el efecto espejo, y que las muestras no son representativas, podemos elaborar un patrón general de las ideologías lingüísticas de individuos amazigh y quechua que viven en Cataluña y no han experimentado el efecto espejo, y de individuos que sí que lo han experimentado. La Tabla 20 resume estas ideologías lingüísticas y es útil para comparar la afectación del efecto espejo, que funciona diferentemente para las dos comunidades. 


\begin{tabular}{|c|c|c|}
\hline & Sin efecto espejo & Efecto espejo \\
\hline Amazighs & $\begin{array}{l}\text { - } \quad \text { Castellano como lengua } \\
\text { común, algún conocimiento de } \\
\text { catalán. } \\
\text { - } \quad \text { Catalán valorado como útil } \\
\text { para el mercado laboral y la } \\
\text { escuela. } \\
\text { - } \quad \text { Identidad Española-marroquí, } \\
\text { a veces identidad } \\
\text { musulmana/islámica. } \\
\text { Importancia del árabe, sobre } \\
\text { todo por razones religiosas. } \\
\text { Indiferencia hacia lenguas } \\
\text { minorizadas, vistas como no } \\
\text { útiles y con valor auténtico. }\end{array}$ & $\begin{array}{l}\text { - } \quad \text { Catalán como lengua } \\
\text { común/preferente. } \\
\text { - } \quad \text { Preferencia del catalán por encima } \\
\text { del castellano, alto conocimiento de } \\
\text { catalán. } \\
\text { - } \quad \text { Identidad catalano-amazigh. } \\
\text { - } \quad \text { Activismo amazigh y defensa de las } \\
\text { lenguas minorizadas y el } \\
\text { plurilingüismo. "Todas las lenguas son } \\
\text { iguales" (A1H45) }\end{array}$ \\
\hline Quechuas & $\begin{array}{ll}\text { - } & \text { Ideología monolingüista } \\
\text { castellana. } \\
\text { - } \quad \text { Identidad del estado-nación de } \\
\text { origen o latinoamericana. } \\
\text { - } \quad \text { Ideologías negativas (rechazo) } \\
\text { hacia el catalán, a veces } \\
\text { neutrales, aunque se acepta } \\
\text { como importante para la } \\
\text { escuela y el mercado laboral. } \\
\text { Quechua como lengua } \\
\text { auténtica, importante solo para } \\
\text { la identidad y la tradición. }\end{array}$ & $\begin{array}{l}\text { - } \quad \text { Conocimiento de catalán en distintos } \\
\text { niveles, pero uso menor. } \\
\text { - Catalán como lengua auténtica, } \\
\text { castellano como lengua anónima. } \\
\text { Defensa del plurilingüismo. } \\
\text { - } \quad \text { Activismo quechua. } \\
\text { - Identidad quechua y catalana, no } \\
\text { incompatible con otras. }\end{array}$ \\
\hline
\end{tabular}

Tabla 20. Resumen de las ideologías lingüísticas en relación al efecto espejo

Como se puede observar, las ideologías lingüísticas están altamente afectadas por el efecto espejo. El efecto principal y común en las dos comunidades es que, antes de verse afectados por el proceso del efecto espejo, la ideología lingüística prevalente es de cariz monolingüista o jerárquico. Después de pasar por el proceso que lleva a la Fase 2, prevalecen las ideologías lingüísticas favorables al plurilingüismo o a la igualdad de las lenguas (véase Comellas 2006: 426; Cortès-Colomé et al. 2016: 275).

En el caso de la comunidad quechua, se observa que el efecto espejo modifica las ideologías lingüísticas especialmente sobre la lengua minorizada propia (el quechua), mientras que para la comunidad amazigh las modifica especialmente sobre la lengua minorizada local (el catalán). Por un lado, la transposición bidireccional es común en todos los casos. La dicotomía entre auténtico y anónimo, por otro lado, solo parece modificarse en el caso de la comunidad amazigh. En el caso de la comunidad quechua, el castellano sigue siendo la lengua anónima y no cambia de rol ni de estatus. 


\subsection{Factores influyentes en las ideologías lingüísticas y el efecto espejo}

Como hemos podido comprobar a través de las entrevistas y las encuestas, las ideologías lingüísticas de los quechua y los amazigh son muy diferentes, aun habiendo experimentado el efecto espejo, ciertas percepciones sociolingüísticas prevalecen. Hay varios factores que pueden influir o determinar tanto las ideologías lingüísticas como la posibilidad de pasar por el proceso que lleva al efecto espejo. Los factores comunes para las dos comunidades son los siguientes:

- La ideología monolingüista previa: es bastante común entre la comunidad quechua, mientras que es menos común entre la comunidad amazigh. Estas ideologías se ven reflejadas en los datos cuantitativos analizados, y explican por qué encontramos menos casos de efecto espejo entre los quechuas. También explica que la afectación del efecto espejo sobre las ideologías lingüísticas de los quechuas sea menor que en las ideologías lingüísticas de los amazigh.

- El acceso y conocimiento del catalán: Como hemos visto en el caso del participante $\mathrm{A} 4 \mathrm{H} 25$, en el que sus hermanos pequeños se educaron en un centro con más presencia de castellano y presentan un comportamiento lingüístico diferente, el acceso al catalán puede ser determinante para desencadenar el efecto espejo. En la Tabla 21 se muestra que hay una clara correlación entre el hallazgo del efecto espejo y la presencia de catalán en la entrevista para los datos cualitativos:

- El conocimiento previo del castellano (lengua dominante en Cataluña): el hecho de que el castellano sea la lengua dominante compartida de catalanes y quechuas facilita la integración de los quechuas en la sociedad, que no necesitan aprender catalán. A su vez, dificulta el aprendizaje de catalán, que es percibido como un esfuerzo extra e innecesario, aunque se perciba importante para el trabajo y la escuela y se quiera que los hijos lo aprendan (Comellas 2006: 424). También hay muchos amazigh que aprenden castellano antes que catalán por varias razones -la mayor es que es la lengua de la calle en las zonas de clase trabajadora, clase a la que pertenecen la mayoría de migrantes marroquíes y algerianos- (Pujolar 2009: 91). En este testimonio, la participante A7D40 explica que saber castellano dificulta aprender catalán, y que con el castellano se puede vivir sin problemas en Cataluña:

Lengua y migración / Language and Migration 12:1 (2020) Monográfico, 127-173

Edición impresa: ISSN 1889-5425. Edición en línea: ISSN 2660-7166. @ U Universidad de Alcalá 


\begin{tabular}{|l|l|l|}
\hline Participante & Efecto espejo & Lengua de la entrevista \\
\hline A1H45 & Sí & Catalán \\
\hline A2H40 & Sí & Catalán \\
\hline A3D20 & Sí & Catalán \\
\hline A4H20 & Sí & Catalán \\
\hline A5D20 & No & Castellano \\
\hline A6H40 & Sí & Catalán \\
\hline A7D40 & Sí & Castellano y catalán \\
\hline A8D40 & Sí & Catalán \\
\hline A9H40 & Sí & Catalán \\
\hline Q1D45 & No & Castellano \\
\hline Q2H45 & No & Castellano \\
\hline Q3D50 & No & Castellano \\
\hline Q4H50 & No & Castellano \\
\hline Q5D40 & Sí & Castellano y catalán \\
\hline Q6H50 & Sí & Castellano y catalán \\
\hline
\end{tabular}

Tabla 21. Efecto espejo y lengua de la entrevista

Investigador [TPC]: Sabías alguna de las dos lenguas antes de venir?

A7dD40: Lengua española. Porque en mis estudios universitarios tenía 3 horas de lengua española.

Investigador: ¿Qué nivel tenías antes de venir?

A7dD40: Básico.

Investigador: Cuando llegaste, ¿hiciste clases de catalán y castellano?

A7dD40: Sólo catalán.

Investigador: Un curso de 50 horas, ¿̇verdad?

A7D40: Sí. Sólo catalán. Castellano no, castellano lo he aprendido así [chasquea los dedos]. Catalán he hecho 50 horas. Y me da vergüenza hablarlo, porque lo entiendo.

Investigador: ¿ Y cuáles crees que son las barreras para acceder al catalán?

A7D40: La facilidad de hablar castellano [ríe]. ¡Claramente!

- Acomodación o convergencia lingüística y racialización: relacionado con el factor anterior, la acomodación lingüística provoca un cambio lingüístico de los catalanohablantes hacia hablantes de la lengua dominante -castellano- y personas percibidas de fuera de la comunidad -que también implica su racialización (Boix 1993; Vila y Galindo 2012). Esto es una barrera para el aprendizaje de catalán, que es protegido como elemento intracomunitario y por ende no es compartido con elementos percibidos como extracomunitarios como consecuencia de la minorización histórica. 
Q1D45: He estado trabajando desde que llegué. No tuve tiempo de aprender catalán bien. Casi todo el mundo me habla siempre en español.

- Clase social y género: es bien conocido que en Cataluña la clase trabajadora tiende a ser más castellanohablante y la clase media más catalanohablante (Pujolar 2009: 91). La inmigración marroquí y latinoamericana se suele integrar en los espacios de clase trabajadora local y, por tanto, en un entorno sociolingüístico con menos presencia de catalán. A su vez, también hay diferencias de género, especialmente en lo que atañe a la comunidad amazigh, como vemos en el siguiente ejemplo:

A3D20: Mis padres trabajan todo el día. Mi padre habla castellano, lo aprendió en la calle, en el trabajo. Mi madre no habla ni catalán ni castellano. Trabaja en casa. [TPC]

A continuación se presentan los factores influyentes y se analizan las dos comunidades de forma separada. Los factores particulares de la comunidad quechua son:

- Lengua dominante común: como hemos explicado, el conocimiento previo de castellano, y especialmente el hecho de que sea también la lengua dominante de la comunidad quechua, previene a los quechuas de aprender catalán (Comellas 2006: 424).

- Racialización: la racialización de los quechuas es muy acusada y empieza en sus países de origen -cosa que no pasa en Marruecos-, llegando a suponer un complejo racial para los indígenas americanos. La oposición en Latinoamérica de “+indígena” a “-indígena” no existe en Europa (Van Dijk 2005). Sin embargo, este complejo es trasladado a Europa una vez en Cataluña:

Q5D40: Hay diferencias raciales por el color de la piel. Los más blancos no quieren hablar quechua, una lengua discriminada y estigmatizada. No quieren relacionarse con el mundo indígena, de la gente más oscura de piel. [...] Pero yo soy mestiza, tengo una parte indígena. Y estoy orgullosa de ella y no me gusta que me digan que soy más blanca y menos indígena como cosa positiva. Cuando era joven sí que quería aparentar ser más blanca. Cuanto más blanca mejor.

Los factores particulares de la comunidad amazigh son:

- Primavera amazigh: el reciente movimiento amazigh, especialmente en las regiones de Cabília y el Rif, ha despertado un senti-

Lengua y migración / Language and Migration 12:1 (2020) Monográfico, 127-173

Edición impresa: ISSN 1889-5425. Edición en línea: ISSN 2660-7166. @C Universidad de Alcalá 
miento y sensibilización de la identidad amazigh y ha estrechado lazos de solidaridad con otros movimientos nacionales, como el catalán (Maddy-Weitzman 2012).

- Arabización e islamización: la arabización histórica -especialmente en el mundo urbano- y la islamización -que implica una identidad basada en la religión como hecho diferencial y que deja el hecho nacional como secundario- son procesos que dificultan la identificación de los amazigh con Cataluña y los asimilan a identidades, culturas, lenguas e ideologías lingüísticas dominantes y mayoritarias (El Aissati 2001).

A6H40: Hay gente que dice que son marroquíes por encima de todo. Hay gente que dice que son musulmanes: su identidad es la religión, el islam. Hay gente, la mayoría, que sí que dicen que son amazigh por encima de la religión o el estado.

\subsection{Comparación de las ideologías lingüísticas de los quechua y amazigh con las ideologías lingüísticas de latinoamericanos y marroquíes}

Para comparar las ideologías lingüísticas de los grupos minorizados con los grupos dominantes, se tiene que distinguir entre individuos minorizados que no han experimentado el efecto espejo e individuos minorizados que sí lo han experimentado. Así, las ideologías lingüísticas del primer grupo son parecidas a las ideologías lingüísticas del grupo dominante, mientras que las ideologías lingüísticas del segundo grupo son diferentes.

En el caso de la comunidad quechua, las ideologías lingüísticas coinciden con aquéllas descritas para los latinoamericanos. De hecho, la identificación de muchos participantes como "andinos" o "americanos" tiene que ver con una adscripción identitaria mayor que el estado nación. El catalán es valorado como importante como ascensor social y en ciertos sectores laborales, pero hay muy poca competencia de esta lengua y tiene asociaciones negativas y a veces hostiles. El componente de la racialización es compartido por otros latinoamericanos. El castellano se considera como la lengua más importante, la lengua anónima de facto, y hay muchas referencias al inglés y su importancia a nivel internacional. Dominan las ideologías y prácticas lingüísticas monolingües con el castellano.

Los quechuas que han experimentado el efecto espejo difieren en dos aspectos esenciales. El primero es la revalorización de la identi- 
dad indígena propia, lo que guarda relación con una menor ocultación étnico-lingüística y un menor autoodio en una lucha contra la racialización sufrida. Por otro lado, las ideologías lingüísticas tienden al multilingüismo y multiculturalismo, aunque no se traducen en cambios en las prácticas lingüísticas y en una competencia alta en catalán.

En lo que atañe a la comunidad amazigh, los individuos que no han experimentado el efecto espejo tienen ideologías lingüísticas ligeramente más favorables al multilingüismo y multiculturalismo, pero mantienen la percepción de las lenguas nacionales (árabe y castellano) como lenguas anónimas, útiles y para la comunicación, el francés y el inglés como lenguas internacionales y las lenguas autóctonas, el catalán y el amazigh, como lenguas menos útiles. Sin embargo, al igual que los quechua se considera el catalán útil para ciertos sectores laborales y como ascensor social. También se comparte la idea de que el catalán y el castellano son muy similares y fáciles de aprender, cosa que se traduce en una mayor competencia en catalán de la que tienen los quechua o latinoamericanos.

Las principales diferencias que surgen en las ideologías lingüísticas de los individuos que han experimentado el efecto espejo son hacia la lengua e identidad autóctonas del país de acogida, la catalana. Ello va acompañado por una revalorización de la lengua e identidad propias, la amazigh, que puede haberse dado antes del efecto espejo. Se potencian las ideologías lingüísticas multilingües, la igualdad de todas las lenguas frente a la jerarquización y la percepción de que todas las lenguas son útiles, valorándolas en términos culturales e identitarios y no sólo en número de hablantes.

Se puede concluir, por tanto, que el efecto espejo aporta una variable que crea un grupo nuevo de ideologías lingüísticas que no existe en la comunidad marroquí o latinoamericana de lengua árabe o castellana. Así, las ideologías lingüísticas de quechuas y amazigh que han pasado por el efecto espejo son substancialmente diferentes a aquellas de los individuos no afectados, que se parecen mucho más a las ideologías de su grupo dominante. La coincidencia de las ideologías lingǘsticas de individuos no afectados por el efecto espejo con individuos del grupo dominante se puede explicar por los procesos de asimilación y minorización de los pueblos quechua y amazigh, los cuales han confeccionado un marco mental nuevo basado en el estado-nación y también en criterios raciales en el caso latinoamericano, cosa que ha influido en sus ideologías lingüísticas así como en otros aspectos socioculturales. 


\section{Conclusión}

A lo largo del artículo se han analizado las ideologías lingüísticas de las comunidades amazigh y quechua en Cataluña en relación con fenómeno del efecto espejo. El efecto espejo es un fenómeno que afecta profundamente no solo las ideologías, sino también las prácticas, usos y actitudes lingüísticas. Por primera vez, se ha ampliado el estudio del efecto espejo sobre dos comunidades minorizadas y se ha concretado la definición y explicación del efecto espejo con respecto a los estudios previos, estableciendo un proceso de 3 fases que concuerdan con el perfil ideológico de los participantes estudiados (Cortès-Colomé 2016; Junyent et al. 2011).

Las ideologías lingüísticas de las comunidades amazigh y quechua -y presumiblemente de otras comunidades minorizadas-y las diferencias que pueda haber, intracomunitarias o comparativas, se pueden explicar en relación con el efecto espejo. El efecto espejo es más acusado y tiene mayores efectos en la comunidad amazigh que en la comunidad quechua, por factores como la racialización o el conocimiento previo de castellano, así como las ideologías lingüísticas de la sociedad de origen.

Las ideologías lingüísticas surgidas como resultado del efecto espejo tienden a ser favorables al plurilingüismo y al respeto y tolerancia de todas las lenguas. Así, a falta de datos más concretos, podemos suponer que contribuyen al mantenimiento de las lenguas de herencia y al mantenimiento de la lengua minorizada local, en este caso el catalán. Por otro lado, las ideologías lingüísticas de los participantes quechua y amazigh que no han experimentado el efecto espejo interesantemente se asemejan a las ideologías lingüísticas descritas por los estudios sobre latinoamericanos y marroquíes respectivamente.

Sería de gran interés estudiar las ideologías lingüísticas de otras comunidades minorizadas o hablantes de lenguas con poco prestigio no solo en Cataluña, sino también en otras regiones de España -como el País Vasco- o del mundo -como el Québec-, para aumentar la significación del estudio y su propuesta teórica. Asimismo, este artículo también puede abrir la puerta a líneas de investigación similares que amplíen la muestra y la hagan más representativa para poder generalizar los resultados obtenidos y evitar los sesgos del mismo.

Albert Badosa Roldós

SOAS University of London / Universitat de Barcelona

ORCID: https://orcid.org/0000-0001-9441-2900

Recepción: 17/09/2019; Aceptación: 03/03/2020

Lengua y migración / Language and Migration 12:1 (2020) Monográfico, 127-173 Edición impresa: ISSN 1889-5425. Edición en línea: ISSN 2660-7166. @ Universidad de Alcalá 


\section{Notas}

1 Consultable en: http://www.gela.cat/doku.php?id=llengues [consultado el 10/04/2019]

2 Concepto usado por algunos participantes (Q4H40, Q5D40 Y Q6H50)

3 De ahora en adelante, [TPC]

4 En todos los casos de "castellano y catalán" el entrevistados usó el catalán y el entrevistado el castellano principalmente o catalán y castellano por igual. Los otros casos fueron conversaciones monolingües.

\section{Referencias bibliográficas}

Aalberse, S. y P. Muysken. 2013. "Perspectives on Heritage Languages”. Position paper for the Workshop Structural Changes in Heritage Languages, January 23-25th 2013. Nijmegen: Radboud University, Faculty of Arts \& Centre for Language Studies.

Alarcón, A. y Garzón, L. 2011. Language, Migration and Social Mobility in Catalonia. Leiden, Boston: Brill.

Barrieras, M. y E. Monrós. 2005. "Les llengües a Catalunya". En Les llengües a Catalunya: Quantes llengües s'bi parlen?, M.C. Junyent (ed.), 15-40. Barcelona: Octaedro.

Barrieras, M. 2013. "La cruilla del multilingüisme: les llengües dels catalans al segle XXI". Diversia. Revista de la cátedra sobre diversitat social, 3. 2-37.

Bastardas, A. 1996. Ecologia de les llengües: medi, contactes i dinàmica sociolingüística. Barcelona: Proa.

Boix, E. 1993. Triar no és trair: Identitat i llengua en els joves de Barcelona. Barcelona: Edicions 62.

Boix, E. (ed.) 2015. Urban Diversities and Language Policies in Medium-Sized Linguistic Communities. Bristol: Multilingual Matters.

Boukous, A. 2011. Revitalizing the Amazigh Language. Stakes, Challenges, and Strategies. Rabat: Publication de l'Institut Royal de la Culture Amazighe. Série: Traduction n..$^{\circ} 24$.

Blas-Arroyo, J. L. 1995. “De nuevo el español y el catalán, juntos y en contraste. Estudio de actitudes lingüísticas”. Revista de lingüística teórica y aplicada, 34. 49-62.

Bullock, S. 2014. "Language Ideologies in Morocco". Anthropology Department Honors Papers, 11. Connecticut: Connecticut College.

Comellas, P. 2006. "Representacions lingüístiques a l'ensenyament secundari obligatori públic de Barcelona”. Treballs de Sociolingüistica Catalana, 20. 417-434.

Comellas, P. et al. 2010. "Descobrir les llengües de la immigració: ocultació, prejudicis i altres malentesos". Llengua, Societat i Comunicació, 8. 54-62.

Corona, V. 2016. "Latino trajectories in Barcelona: a longitudinal ethnographic study of Latin American adolescents in Catalonia”. Language, Culture and Curriculum, 29:1. 93-106.

Coronel-Molina, S. 2007. Language policy and planning, and language ideologies in Peru: The case of Cuzco's High Academy of the Quechua Language (Qheswa simi hamut' ana kuraq suntur). $\mathrm{PhD}$ Dissertation. University of Pennsylvania.

Cortès-Colomé, M., M. Barrieras y P. Comellas, P. 2016. "Changes in immigrant individuals' language attitudes through contact with Catalan: the mirror effect”. Language Awareness, 25:4. 272-289.

Direcció General de Política Lingüística (DGPL). 2015. Informe de política lingüística 2015. Generalitat de Catalunya, Departament de Cultura. Online en: http://premsa.gencat.cat/pres_fsvp/docs/2016/11/16/10/58/5221b19f-207d-4bd2ab01-3893d2900a30.pdf [consultado abril 2019].

Lengua y migración / Language and Migration 12:1 (2020) Monográfico, 127-173

Edición impresa: ISSN 1889-5425. Edición en línea: ISSN 2660-7166. @ Universidad de Alcalá 
Edwards, J. 2010. Minority languages and group identity: Cases and categories. Amsterdam: John Benjamins Publishing Company.

El Aissati, A. 2001. "Ethnic Identity, Language Shift and the Amaizgh voice in Morocco and Algeria”. Race, Gender and Class, 8:3. 57-69.

Fidalgo, M. 2015. L'ensenyament de llengua $i$ cultura d'origen a Catalunya. Tesis Doctoral, Barcelona: Universitat of Barcelona.

Fishman, J. 1991. Reversing Language Shift. Theoretical and Empirical Foundations of Assistance to Threatened Languages. Clevedon: Multilingual Matters.

Foddy, W. 1993. Constructing questions for interviews and questionnaires: Theory and practice in social research. Cambridge: Cambridge University Press.

Garzón, L. 2012. “Globalization, Latin American Migration and Catalan: Closing the Ring”. Sustainability, 2012:4. 2498-2512.

Gràcia, Ll. 2010. "El Quítxua. Estudi comparatiu entre la gramàtica del català i la del quítxua”. Col.lecció Llengua, immigració $i$ ensenyament del català, n. ${ }^{\circ}$ 13. Barcelona: Generalitat de Catalunya, Departament de Benestar i Família.

Heller, M., J. Pujolar y S. Pietikäinen. 2017. Critical Sociolinguistic Research Methods. Londres: Routledge, Studying Language Issues That Matter.

Institut d'Estadística de Catalunya (IDESCAT) (2015). Enquesta d'usos lingüístics de la població 2013 (EULP 2013). Barcelona: Generalitat de Catalunya. https://www.idescat.cat/cat/idescat/publicacions/cataleg/pdfdocs/eulp2013.pdf [consultado abril 2019]

Institut d'Estadística de Catalunya (IDESCAT) (2005). Estadística d'usos lingüístics de Catalunya 2003 (EULC 2003). Barcelona: Generalitat de Catalunya. https://www.idescat.cat/cat/idescat/publicacions/cataleg/pdfdocs/eulc2003.pdf [consultado abril 2019]

Junyent, M. C. et al. 2011. “Canvi de representacions lingüístiques de parlants al·loglots per contacte amb la situación lingüística catalana”. Recerca i immigració, III. 93-109.

King, K. A. y N. Hornberger. 2004. Quechua Sociolinguistics. Berlin: Mouton de Gruyter.

King, K. y J. Ennser-Kananen. 2013. "Heritage Languages and Language Policy”. En The Encyclopedia of Applied Linguistics, C. Chapelle (ed.). Oxford: Blackwell/Wiley.

Labov, W. 1972. Sociolinguistic Patterns. Philadelphia: University of Pennsylvania Press.

Larrea, I. 2017. Les Actituds lingüistiques dels immigrants panjabis adults a Catalunya. Tesis Doctoral. Barcelona: Universitat Pompeu Fabra.

Lamuela, X. 2005. El berber: estudi comparatiu entre la gramàtica del català $i$ la del berber o amazig. Barcelona: Generalitat de Catalunya, Departament de Benestar i Família.

Low, G. 1999. "What respondents do with questionnaires: accounting for incongruity and fluidity”. Applied Linguistics, 20(4). 503-33.

Maddy-Weitzman, B. 2012. "Arabization and Its Discontents: The Rise of the Amazigh Movement in North Africa". The Journal of the Middle East and Africa, 3:2. 109-135.

Meyerhoff, M., C. Adachi, G. Nanbakhsh y A. Strycharz. 2012. "Sociolinguistic Fieldwork". En The Oxford Handbook of Linguistic Fieldwork, Nick Thieberger (ed.), 15-34. Oxford: Oxford University Press.

Newman, M. 2011. "Different ways to hate a language in Catalonia: Interpreting low solidarity scores in language attitude studies". En Selected proceedings of the 5 th workshop on Spanish sociolinguistics, Jim Michnowicz y Robin Dodsworth (eds.), 39- 49. Somerville, MA: Cascadilla Proceedings Project.

Ogoshi, N. y Hayasi, N. 2004. Attitudes to Langange Use in a Multi-Cultural Setting: A Report on Questionnaire Surveys of Korean/Japanese and Turkish/German Speakers. Collection 'Endangered Languages of the Pacific Rim'. Kyoto: Nakanishi Printing.

Patiño-Santos, A. 2018. “ «No-one told me it would all be in Catalan!» - narratives and language ideologies in the Latin American community at school”. International Journal of the Sociology of Language 2018, 250. 59-86.

Pujolar, J. 2009. "Immigration in Catalonia: marking territory through Language". In Globalization and Language Contact: Spatiotemporal Scales, Migration Flows, and Communicative Practices, Mike Baynham y Jim Collins (eds.). London: Continuum.

Lengua y migración / Language and Migration 12:1 (2020) Monográfico, 127-173 Edición impresa: ISSN 1889-5425. Edición en línea: ISSN 2660-7166. C Universidad de Alcalá 
Pujolar, J., y M. Puigdevall. 2015. “Linguistic 'Mudes': How to Become a New Speaker in Catalonia." International Journal of the Sociology of Language, 231. 167-187.

Sallabank, J. 2013. Attitudes to Endangered Languages. Identities and Policies. Cambridge: Cambridge University Press.

Sanvicén-Torné, P. 2017. "Dones i transmissió lingüística en llars d'origen immigrant. Impactes, reptes i oportunitats”, Treballs de Sociolingüística Catalana, 27. 149-174.

Sanvicén-Torné, P. 2016. "Dones marroquines i aprenentatge del català. Anàlisi sociològica des d'una perspectiva de gènere”. Treballs de Sociolingüística Catalana, 26. 269-284.

Van Deusen-Scholl, N. 2003. "Toward a definition of heritage language: Sociopolitical and pedagogical considerations". Journal of Language, Identity, and Education, 2(3). 211-30.

Van Dijk, T. 2005. Racism and Discourse in Spain and Latin America. Amsterdam: John Benjamins Publishing Company.

Vila, F. X., y M. Galindo. 2012. "Sobre la història i l'extensió de la norma de convergència lingüística a Catalunya”. En Posar-hi la base: Usos i aprenentatges lingüístics en el domini català, F.X. Vila (ed.) 31-45. Barcelona: Institut d'Estudis Catalans.

Vila, F. X., Sorolla, N. y Larrea, I. 2013. “Les vies per a l'aprenentatge lingüístic del jovent d'origen marroquí establert a Catalunya”. En Noves migracions i llengües, Vila, F. X.; Salvat, Eulàlia (eds.) 147-198. Barcelona: Agrupación de Editores y Autores Universitarios, Universitat de Barcelona.

Woolard, K. y Frekko, S. 2013. "Catalan in the twenty-first century: romantic publics and cosmopolitan communities". International Journal of Bilingual Education and Bilingualism, 16:2. 129-137.

Woolard, K. 2008. "Language and identity choice in Catalonia: The interplay of contrasting ideologies of linguistic authority". En Lengua, nación e identidad. La regulación del plurilingüismo en España y América Latina, K. Süselbeck, U. Mühlschlegel y P. Masson (eds.), 303-323. Frankfurt am Main Vervuert/Madrid: Iberoamericana. 
Anexo

La Tabla 22 lista todos los participantes según la nomenclatura de la Tabla 1.

\begin{tabular}{|l|l|}
\hline A1H45 & Q1D45 (Bolivia) \\
\hline A2H40 & Q2H45 (Perú) \\
\hline A3D20 & Q3D50 (Perú) \\
\hline A4H20 & Q4H50 (Ecuador) \\
\hline A5D20 & Q5D40 (Perú) \\
\hline A6H40 & Q6H50 (Perú) \\
\hline A7D40 & \\
\hline A8D40 & \\
\hline A9H40 & \\
\hline
\end{tabular}

Tabla 22. Lista de todos los participantes entrevistados según la convención de nomenclatura

Lengua y migración / Language and Migration 12:1 (2020) Monográfico, 127-173 Edición impresa: ISSN 1889-5425. Edición en línea: ISSN 2660-7166. (C) Universidad de Alcalá 